\title{
. Formation of Protonated Glycine Isomers in the Interstellar Medium
}

\author{
2 Miguel Sanz-Novo, Antonio Largo, $\odot$ Pilar Redondo, and Carmen Barrientos*๑ \\ 3 Departamento de Química Física y Química Inorgánica, Facultad de Ciencias, Universidad de Valladolid, 47011 Valladolid, Spain \\ 4 S Supporting Information
}

\begin{abstract}
A computational study of protonated glycine isomers with $\left[\mathrm{H}_{6} \mathrm{C}_{2} \mathrm{O}_{2} \mathrm{~N}\right]^{+}$molecular formula has been carried out. All of them are possible products of the reaction between protonated hydroxylamine and acetic acid. All reaction processes that could form the $\left[\mathrm{H}_{6} \mathrm{C}_{2} \mathrm{O}_{2} \mathrm{~N}\right]^{+}$isomers considered in this work are exothermic except for those initiated by the most stable isomer of protonated hydroxylamine which give $\mathrm{CH}_{3} \mathrm{CONH}_{2}{ }^{+} \mathrm{OH}$ and $\mathrm{CH}_{3} \mathrm{COHNOH}_{2}{ }^{+}$isomers. The analysis of the potential energy surfaces corresponding to the reaction of protonated hydroxylamine and acetic acid has been focused on the most abundant products, namely, $\mathrm{CH}_{3} \mathrm{CONH}_{2}{ }^{+} \mathrm{OH}$, $\mathrm{CH}_{3} \mathrm{COONH}_{3}{ }^{+}$, and $\mathrm{CH}_{3} \mathrm{C}(\mathrm{OH})^{+} \mathrm{ONH}_{2}$, obtained from a previous chemical dynamics simulations study. From this

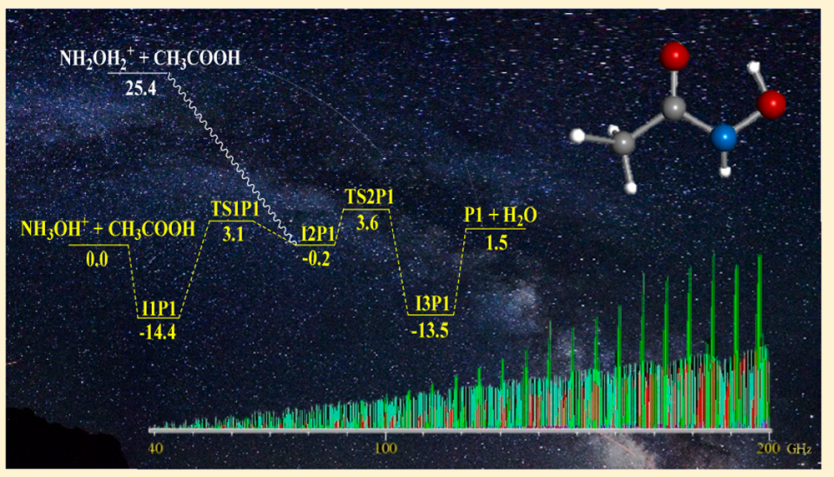
analysis we found that even if the reactions of formation of the $\mathrm{CH}_{3} \mathrm{COONH}_{3}{ }^{+}$and the $\mathrm{CH}_{3} \mathrm{C}(\mathrm{OH})^{+} \mathrm{ONH}_{2}$ isomers are exothermic processes, significant activation barriers were found in the paths leading to these products. The only exothermic process $\left(\Delta E=-23.9 \mathrm{kcal} \mathrm{mol}^{-1}\right.$ at the $\operatorname{CCSD}(\mathrm{T})$ level $)$ with no net activation barrier was initiated by the high-energy isomer of protonated hydroxylamine, which leads to the $\mathrm{CH}_{3} \mathrm{CONH}_{2}{ }^{+} \mathrm{OH}$ isomer. Therefore, the formation of this isomer could be feasible under interstellar conditions from the reaction of the less stable isomer of protonated hydroxylamine and acetic acid. In addition, an analysis of their neutral counterparts, with $\left[\mathrm{H}_{5} \mathrm{C}_{2} \mathrm{O}_{2} \mathrm{~N}\right]$ molecular formula, has been carried out. The relevant spectroscopic parameters for $\left[\mathrm{H}_{6} \mathrm{C}_{2} \mathrm{O}_{2} \mathrm{~N}\right]^{+}$and $\left[\mathrm{H}_{5} \mathrm{C}_{2} \mathrm{O}_{2} \mathrm{~N}\right]$ isomers that could help in their laboratory or astronomical detection, by radioastronomy or infrared spectroscopy, are reported.

KEYWORDS: astrochemistry, interstellar medium general, interstellar medium molecules, interstellar medium structure, molecular data
\end{abstract}

\section{INTRODUCTION}

28 Amino acids are essential components of living systems since 29 they play a crucial role as building blocks of proteins. Amino 30 acids were the first prebiotic molecules to be identified in the 31 Miller experiment ${ }^{1,2}$ from the reaction of simple organic 32 molecules. On the other hand, taking into account their 33 presence in some chondritic meteorites, ${ }^{3-5}$ amino acids should 34 be one of the easiest biomonomers to synthesize. ${ }^{6}$ Despite 35 several radioastronomical searches, so far the smallest amino 36 acid, glycine, has not been conclusively identified in the 37 interstellar medium (ISM). ${ }^{7-10}$ However, recently, Altwegg et $38 \mathrm{al}^{11}$ have reported the presence of volatile glycine together 39 with the precursor molecules methylamine and ethylamine in 40 the coma of comet 67P/Churyumov-Gerasimenko. The 41 observation of amino acids in the interstellar medium and in 42 solar system bodies should be of crucial importance for 43 revealing the chemistry that may have led to life's origin. ${ }^{12}$

44 There is a question as to whether glycine will ever be 45 detectable even if present, given the difficulties for its possible 46 detection in space. ${ }^{13}$ One of these difficulties arises from its 47 rotational spectrum features with relatively weak lines due to 48 its large molecular partition function. Thus, search of the target 49 transitions could be hindered by the emission of other 50 molecules. Second, amino acids are highly susceptible to UV photodestruction and they will likely be destroyed during the 51 lifetime of a typical interstellar cloud. ${ }^{12}$ Consequently, they 52 only survive in shielded environments. Finally, from a 53 chemical-physics point of view, it might happen that efficient 54 synthetic routes for the production of amino acids under 55 interstellar conditions do not exist.

In this regard, exothermic ion-molecule reactions between 57 positive ions and neutral molecules play a crucial role in the 58 synthesis of organic interstellar molecules in the gas phase ${ }^{14} 59$ since these processes tend to have no activation energy 60 barriers. In particular, the feasibility of the gas-phase formation 61 of protonated glycine from the reaction of acetic acid and 62 protonated hydroxylamine was studied by Bohme and co- 63 workers. ${ }^{15,16}$ Both reactants are either detected or plausible 64 interstellar molecules. Acetic acid was detected in the $3 \mathrm{~mm} 65$ region toward the massive star-forming region $\mathrm{Sgr}$ B2 $(\mathrm{N}-66$

Special Issue: Complex Organic Molecules (COMs) in StarForming Regions

Received: March 14, 2019

Revised: $\quad$ May 2, 2019

Accepted: May 15, 2019

Published: May 15, 2019 
$67 \mathrm{LMH})^{17}$ as well in the additional hot core source W51e2. ${ }^{18}$ So 68 far, hydroxylamine has not been detected in space but it is 69 considered a likely target of detection with ALMA. ${ }^{19}$ N-bearing 70 molecules are precursors of prebiotic molecules, and among 71 them hydroxylamine appears to be one of the best candidates. 72 It is considered to be one of the main precursors in the 73 formation of amino acids in the interstellar medium. The 74 search for hydroxylamine in space has been devoted a lot of 75 attention in the most recent years, and many theoretical and 76 experimental studies have been focused on the processes of 77 formation of this compound. The chemical diversity and 78 complexity found in space could be explained as the result of 79 gas, grain, and gas-grain interactions in dense interstellar 80 clouds. In the most recent years, the study of surface processes 81 has received a growing interest in finding an alternative to gas82 phase reactions and also in understanding the composition of 83 icy mantles. In space, some species are formed from dust grains 84 mantles. In this context, from different laboratory experimental 85 studies $^{19-23}$ it was concluded that hydroxylamine could be 86 formed easily in solid phase and then it could desorb through a 87 temperature-induced process into the gas phase. Recently, 88 Jonusas and $\mathrm{Krim}^{24}$ have reported a possible answer to the 89 nondetection of hydroxylamine trying to make sense of the 90 inconsistency between the high abundances of hydroxylamine 91 found in experimental studies and its nondetection in 92 astronomical sources. From a detailed study of the thermal 93 desorption mechanism, the authors concluded that the process 94 of heating of $\mathrm{NH}_{2} \mathrm{OH}-\mathrm{H}_{2} \mathrm{O}$ ices that led to a decomposition 95 of hydroxylamine into $\mathrm{HNO}, \mathrm{NH}_{3}$, and $\mathrm{O}_{2}$ could reduce 96 considerably the abundance of hydroxylamine molecules 97 releasing in the gas phase. This thermal desorption mechanism 98 might be the primary explanation for the nondetection, so far, 99 of hydroxylamine in space. However, the presence of this 100 species in interstellar medium remains an open topic, and it 101 cannot be discarded as reactant for plausible interstellar 102 processes.

103 From their selected-ion flow tube (SIFT) experiments, 104 Bohme et al. ${ }^{15,16}$ demonstrated the gas-phase ionic syntheses 105 of glycine from smaller molecules found in space. Specifically, 106 the authors ${ }^{15,16}$ concluded that protonated glycine could be 107 formed by the reaction of the most energetic form of 108 protonated hydroxylamine, $\mathrm{NH}_{2} \mathrm{OH}_{2}{ }^{+}$and acetic acid. When 109 the reaction started from the lower energy form of protonated 110 hydroxylamine, $\mathrm{NH}_{3} \mathrm{OH}^{+}$, only clusters with carboxylic acids 111 were formed. These studies were very interesting, since the 112 formation of precursors of glycine was reported. Based on 113 those promising results, we carried out a computational study 114 of the reactions of ionized and protonated hydroxylamine with 115 acetic acid. ${ }^{25}$ From the study, we concluded that the reaction 116 of the most stable protonated isomer of hydroxylamine, $117 \mathrm{NH}_{3} \mathrm{OH}^{+}$, with acetic acid involves a high activation barrier 118 (more than $27 \mathrm{kcal} \mathrm{mol}^{-1}$ at the $\operatorname{CCSD}(\mathrm{T})$ level). Only the 119 higher energy isomer, $\mathrm{NH}_{2} \mathrm{OH}_{2}{ }^{+}$, led to a sensibly lower energy 120 barrier (about $2.3 \mathrm{kcal} \mathrm{mol}^{-1}$ at the $\operatorname{CCSD}(\mathrm{T})$ level). 121 Nevertheless, an estimate of the reaction coefficient at low 122 temperatures gave very low values. Therefore, it seemed that 123 precursors of interstellar glycine could not be efficiently 124 produced from the reactions of hydroxylamine-derived ions 125 with acetic acid.

126 Recently, Jeanvoine et al. ${ }^{26}$ have investigated the dynamics 127 of the above-mentioned reactions. The authors concluded that 128 both tautomers of protonated hydroxylamine were able to 129 react with neutral acetic acid under gas-phase conditions, given that some translational energy is provided. However, even 130 though reaction products had a mass-overcharge ratio, $\mathrm{m} / z 131$ 76 , they did not have the structure of protonated glycine, but a 132 distribution of isomeric structures all different from protonated 133 glycine was found. These simulation results suggested that 134 astrophysicists should look for spectroscopic signatures of 135 these glycine isomers in the ISM, eventually.

In the present work, following Jeanvoine et al.'s ${ }^{26}{ }_{137}^{136}$ conclusions, we have carried out a computational study of 138 the potential energy surfaces (PES) corresponding to the 139 reactions of formation of different products, all of them with 140 mass-overcharge ratio, $m / z 76$, and $\left[\mathrm{H}_{6} \mathrm{C}_{2} \mathrm{O}_{2} \mathrm{~N}\right]^{+}$molecular 141 formula (denoted as $\mathrm{P} 1-\mathrm{P} 8$ ). These products together with a 142 water molecule are obtained from the reaction of protonated 143 hydroxylamine and acetic acid. For each one of the reaction 144 products we provide structural data and spectroscopic 145 properties that could guide their possible search in the ISM. 146 In addition, we will also give information for their neutral 147 counterparts, with $\left[\mathrm{H}_{5} \mathrm{C}_{2} \mathrm{O}_{2} \mathrm{~N}\right]$ molecular formula and denoted 148 as $\mathrm{P} 1 \mathrm{~N}-\mathrm{P} 8 \mathrm{~N}$, with the aim being to aid their laboratory or 149 astronomical detection by radioastronomy or infrared (IR) 150 spectroscopy as well as to analyze the behavior of these isomers 151 upon protonation.

The stability of different isomers of neutral and protonated 153 glycine was previously computed ${ }^{27}$ at a highly correlated 154 coupled cluster level using the geometry and zero-point 155 vibrational energy (ZPE) obtained through density functional 156 theory. Some of the isomers considered in that study are 157 among the species included in both the neutral and protonated 158 systems analyzed in the present work. In this regard, it should 159 be remarked that our main goal here will not be to carry out an 160 exhaustive study for the most stable isomers of protonated and 161 neutral glycine; otherwise, it will be to provide structural and 162 spectroscopic information for the isomers of protonated 163 glycine concerned with the chemical dynamics simulations 164 study. ${ }^{26}$ We will focus our attention on the formation processes 165 of the most abundant products found in the chemical dynamics 166 simulation study ${ }^{26}$ of the reaction between acetic acid and 167 hydroxylamine. Nevertheless, we have carried out a compre- 168 hensive structural and spectroscopic description for all of the 169 isomers of protonated (P1-P8) and neutral (P1N-P8N) 170 glycine with the aim to aid their laboratory or astronomical 171 detection by radioastronomy or infrared (IR) spectroscopy. $\quad 172$

To the best of our knowledge, among the neutral isomers 173 studied in the present work, only methyl carbamate 174 $\left(\mathrm{CH}_{3} \mathrm{OCONH}_{2}\right)$ has been tentatively searched for in the hot 175 molecular cloud W51e2 and in the intermediate mass protostar 176 IRAS2 $1391+58502 .{ }^{28}$ Grooner et al. ${ }^{29}$ studied its millimeter- 177 and sub-millimeter-wave spectrum providing rotational data in 178 a wide frequency range. What's more, glycolamide 179 $\left(\mathrm{HOCH}_{2} \mathrm{CONH}_{2}\right)$ has also been characterized by free jet 180 millimeter-wave spectroscopy in the $60-78.3 \mathrm{GHz}$ frequency 181 range in combination with a computational study. ${ }^{30}$ To the 182 best of our knowledge, neither structural nor spectroscopic 183 information is available for the rest of the neutral species.

184

\section{COMPUTATIONAL METHODS}

The geometries of all the species (reactants, intermediates, 185 transition states, and products) studied in this work were first 186 optimized using the density functional theory (DFT) within 187 the hybrid B3LYP formalism ${ }^{31,32}$ coupled with the correlation- 188 consistent polarized valence triple- $\zeta$, cc-pVTZ basis set. ${ }^{33,34} 189$ Subsequently, structures were optimized at the second-order 190 


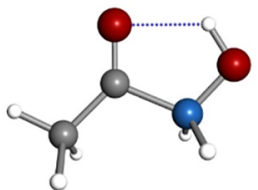

P1

N-protonated N-hydroxyacetamide $\mathrm{CH}_{3} \mathrm{CONH}_{2}{ }^{+} \mathrm{OH}$

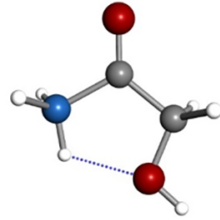

P5

N-protonated Glycolamide $\mathrm{OHCH}_{2} \mathrm{CONH}_{3}$

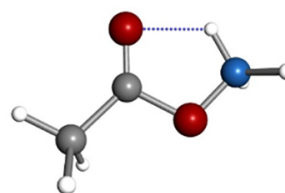

P2

N-protonated

O-Acetylhydroxylamine $\mathrm{CH}_{3} \mathrm{COONH}_{3}{ }^{+}$

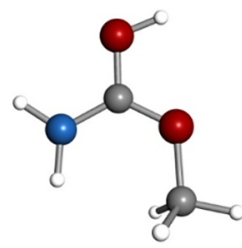

P6

O-protonated Methylcarbamate $\mathrm{CH}_{3} \mathrm{OC}^{+} \mathrm{OHNH}_{2}$

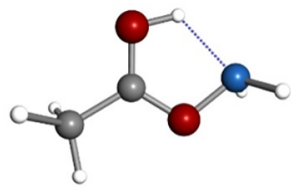

P3

O-protonated

O-Acetylhydroxylamine $\mathrm{CH}_{3} \mathrm{C}^{+} \mathrm{OHONH} \mathrm{H}_{2}$

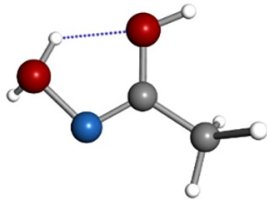

P7

O-protonated

$\mathrm{N}$-Hydroxyacetamidic acid $\mathrm{OH}_{2}^{+} \mathrm{NCOHCH}_{3}$

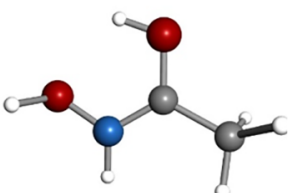

P4

O-protonated

N-hydroxyacetamide

$\mathrm{CH}_{3} \mathrm{C}^{+} \mathrm{OHNHOH}$

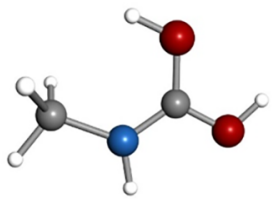

P8

O-protonated

Methylcarbamic acid,

$\mathrm{CH}_{3} \mathrm{NHC}^{+} \mathrm{OHOH}$

Figure 1. Chemical structures of $\left[\mathrm{H}_{6} \mathrm{C}_{2} \mathrm{O}_{2} \mathrm{~N}\right]^{+}(\mathbf{P 1}-\mathbf{P 8})$ isomers optimized at MP2/aug-cc-pVTZ level of theory.

191 Møller-Plesset level ${ }^{35}$ in conjunction with the Dunning's aug192 cc-pVTZ (correlation-consistent polarized valence triple- $\zeta$ 193 including diffuse functions) basis set. ${ }^{33,36}$ On each fully 194 optimized structure, harmonic vibrational frequencies were 195 calculated. This allows one to estimate the zero-point 196 vibrational energy as well as to verify the nature of the 197 stationary points located on the PES, either a true minimum 198 with all vibrational frequencies real or a transition state (TS) 199 with one of the frequencies, and just one, imaginary. To aid in 200 a possible experimental identification by IR spectroscopy, we 201 have computed anharmonic vibrational frequencies for both 202 the protonated isomers: $\left[\mathrm{H}_{6} \mathrm{C}_{2} \mathrm{O}_{2} \mathrm{~N}\right]^{+}$species, and their neutral 203 counterparts, $\left[\mathrm{H}_{5} \mathrm{C}_{2} \mathrm{O}_{2} \mathrm{~N}\right]$ species. Anharmonic frequencies 204 were computed at the MP2 level of theory using the second205 order perturbation treatment (VPT2). ${ }^{37}$ The treatment 206 includes a full cubic force field (CFF) and semidiagonal 207 quartic force constants. In addition, vibration-rotation 208 interaction constants can also be evaluated, from the CFF 209 calculations, allowing for correction of rotational constants, 210 including vibrational effects.

211 In order to compute more accurate energies, we carried out 212 coupled-cluster calculations. Specifically, the coupled-cluster 213 single and double excitation model augmented with a 214 noniterative triple excitation correction, $\operatorname{CCSD}(T),{ }^{38}$ was 215 used in conjunction with the aug-cc-pVTZ basis set ${ }^{33,36}$ on 216 the MP2/aug-cc-pVTZ optimized geometries. The intrinsic 217 reaction coordinate (IRC) technique ${ }^{39,40}$ was used to check 218 the connections between transition-state structures and 219 adjacent minima.

220 The GAUSSIAN $16^{41}$ package of programs was used for all 221 quantum calculations except for the computation of 222 anharmonic corrections. For this purpose, the CFOUR ${ }^{42}$ 223 package was employed.

\section{RESULTS AND DISCUSSION}

224 According to the Bohme et al.'s experiments, ${ }^{15}$ both isomers of 225 protonated hydroxylamine (the most stable one, $\mathrm{NH}_{3} \mathrm{OH}^{+}$, 226 and the high-energy $\mathrm{NH}_{2} \mathrm{OH}_{2}^{+}$) could be obtained in the protonation process of hydroxylamine using $\mathrm{CH}_{5}{ }^{+}$as 227 protonating agent. The energy barrier corresponding to the 228 $\mathrm{NH}_{3} \mathrm{OH}^{+} \rightarrow \mathrm{NH}_{2} \mathrm{OH}_{2}^{+}$isomerization process is $50.71 \mathrm{kcal} / 229$ mol at the $\operatorname{CCSD}(\mathrm{T})$ level of theory; consequently, both 230 isomers, $\mathrm{NH}_{3} \mathrm{OH}^{+}$and $\mathrm{NH}_{2} \mathrm{OH}_{2}{ }^{+}$, could coexist when 231 hydroxylamine is protonated. Neither of them react with $\mathrm{H}_{2} 232$ under space conditions ${ }^{43}$ and therefore both, if present in the 233 interstellar medium, should be able to react with other 234 molecules such as acetic acid.

In principle, acetic acid may react with both isomers of 236 protonated hydroxylamine to produce protonated glycine and 237 water, although other different products also with $\left[\mathrm{H}_{6} \mathrm{C}_{2} \mathrm{O}_{2} \mathrm{~N}\right]^{+}{ }_{238}$ molecular formula could be formed. Both processes can be 239 summarized as follows:

$$
\begin{aligned}
& \mathrm{NH}_{3} \mathrm{OH}^{+}+\mathrm{CH}_{3} \mathrm{COOH} \rightarrow\left[\mathrm{H}_{6} \mathrm{C}_{2} \mathrm{O}_{2} \mathrm{~N}\right]^{+}+\mathrm{H}_{2} \mathrm{O} \\
& \mathrm{NH}_{2} \mathrm{OH}_{2}^{+}+\mathrm{CH}_{3} \mathrm{COOH} \rightarrow\left[\mathrm{H}_{6} \mathrm{C}_{2} \mathrm{O}_{2} \mathrm{~N}\right]^{+}+\mathrm{H}_{2} \mathrm{O}
\end{aligned}
$$

Given the spin multiplicity of the reactants, $\mathrm{NH}_{3} \mathrm{OH}^{+}\left({ }^{1} \mathrm{~A}^{\prime}\right), 243$ $\mathrm{NH}_{2} \mathrm{OH}_{2}{ }^{+}\left({ }^{1} \mathrm{~A}\right)$, and $\mathrm{CH}_{3} \mathrm{COOH}\left({ }^{1} \mathrm{~A}^{\prime}\right)$, the reaction takes 244 place on the singlet potential energy and all of the products are 245 in their singlet electronic state $\left({ }^{1} \mathrm{~A}\right)$.

3.1. Stability and Formation Processes of Protonated 247 Glycine Isomers. In the dynamics simulations study by 248 Jeanvoine et al., ${ }^{26}$ eight products, denoted as P1-P8, are 249 obtained from the reaction of protonated hydroxylamine with 250 acetic acid. The chemical structures of the $\mathrm{P} 1-\mathrm{P} 8$ reaction 251 products are schematized in Figure 1. Before computation of $252 \mathrm{fl}$ reaction energies, we performed a detailed conformational 253 analysis, for each one of the P1-P8 reaction products. It 254 should be noted that, in the case of P1 and P3 products, we 255 have found lowest lying conformational structures including 256 intramolecular hydrogen bonds that are somewhat different 257 from those considered in the work by Jeanvoine et al. ${ }^{26} 258$

In Table 1, we collect the relative energies, with respect to $259 \mathrm{tl}$ reactants, of the possible products that can be formed in the 260 reaction between either $\mathrm{NH}_{3} \mathrm{OH}^{+}$or $\mathrm{NH}_{2} \mathrm{OH}_{2}^{+}$and 261 $\mathrm{CH}_{3} \mathrm{COOH}$ computed at different levels of theory. At the 262 
Table 1. Relative Energies (Referred to Reactants), Including Zero Point Corrections, in $\mathrm{kcal} \mathrm{mol}^{-1}$, Obtained at Different Levels of Theory, for the Reaction between Protonated Hydroxylamine and Acetic Acid Yielding Protonated Glycine $\left(\mathrm{GlyH}^{+}\right)$and Its Structural Isomers (P1-P8)

\begin{tabular}{|c|c|c|c|c|}
\hline reacn $^{a}$ & $\mathrm{~B} 3 \mathrm{LYP}^{b}$ & $\mathrm{MP}^{c}{ }^{c}$ & $\operatorname{CCSD}^{d}$ & $\operatorname{CCsD}(\mathrm{T})^{e}$ \\
\hline $\mathrm{GlyH}^{+}+\mathrm{H}_{2} \mathrm{O}$ & -51.77 & -59.12 & -56.08 & -56.29 \\
\hline GlyH $^{+}+\mathrm{H}_{2} \mathrm{O}$ & -76.59 & -85.41 & -83.62 & -81.69 \\
\hline $\mathbf{P 8}+\mathrm{H}_{2} \mathrm{O}$ & -50.87 & -54.86 & -53.66 & -52.86 \\
\hline P8 $+\mathrm{H}_{2} \mathrm{O}$ & -75.69 & -81.15 & -81.20 & -78.26 \\
\hline $\mathrm{P} 6+\mathrm{H}_{2} \mathrm{O}$ & -48.56 & -51.38 & -50.70 & -49.88 \\
\hline P6 $+\mathrm{H}_{2} \mathrm{O}$ & -73.38 & -77.67 & -78.24 & -75.28 \\
\hline P5 $+\mathrm{H}_{2} \mathrm{O}$ & -31.09 & -38.13 & -35.75 & -36.02 \\
\hline P5 $+\mathrm{H}_{2} \mathrm{O}$ & -55.91 & -64.43 & -63.30 & -61.41 \\
\hline $\mathbf{P 4}+\mathrm{H}_{2} \mathrm{O}$ & -11.49 & -12.74 & -12.84 & -12.83 \\
\hline $\mathbf{P 4}+\mathrm{H}_{2} \mathrm{O}$ & -36.31 & -39.03 & -40.38 & -38.23 \\
\hline $\mathbf{P} 2+\mathrm{H}_{2} \mathrm{O}$ & -8.64 & -11.86 & -9.68 & -10.95 \\
\hline $\mathbf{P 2}+\mathrm{H}_{2} \mathrm{O}$ & -33.46 & -38.15 & -37.23 & -36.35 \\
\hline $\mathbf{P} 3+\mathrm{H}_{2} \mathrm{O}$ & -6.66 & -7.59 & -7.62 & -8.38 \\
\hline $\mathrm{P} 3+\mathrm{H}_{2} \mathrm{O}$ & -31.48 & -33.89 & -35.16 & -33.78 \\
\hline $\mathbf{P 1}+\mathrm{H}_{2} \mathrm{O}$ & 5.42 & 0.89 & 2.71 & 1.52 \\
\hline $\mathbf{P 1}+\mathrm{H}_{2} \mathrm{O}$ & -19.41 & -25.40 & -24.83 & -23.88 \\
\hline P7 $+\mathrm{H}_{2} \mathrm{O}$ & 15.85 & 14.60 & 14.43 & 13.29 \\
\hline $\mathrm{P} 7+\mathrm{H}_{2} \mathrm{O}$ & -8.97 & -11.69 & -22.54 & -12.11 \\
\hline
\end{tabular}

${ }^{a}$ The first entry refers to the $\mathrm{NH}_{3} \mathrm{OH}^{+}+\mathrm{CH}_{3} \mathrm{COOH}$ reaction and the second one to the $\mathrm{NH}_{2} \mathrm{OH}_{2}{ }^{+}+\mathrm{CH}_{3} \mathrm{COOH}$ reaction. ${ }^{b}$ Electronic energy calculated at the $\mathrm{B} 3 \mathrm{LYP} / \mathrm{cc}-\mathrm{pVTZ}$. ${ }^{c}$ Electronic energy calculated at the MP2/aug-cc-pVTZ levels. ${ }^{d}$ Electronic energy calculated at the CCSD/aug-cc-pVTZ//MP2/aug-cc-pVTZ level. ${ }^{e}$ Electronic energy calculated at the $\operatorname{CCSD}(\mathrm{T}) /$ aug-cc-pVTZ// MP2/aug-cc-pVTZ level.
$\operatorname{CCSD}(\mathrm{T})$ level of theory, hydroxylamine protonated in its 263 oxygen atom, $\mathrm{NH}_{2} \mathrm{OH}_{2}^{+}$, was found to lie $25.4 \mathrm{kcal} \mathrm{mol}^{-1} 264$ higher in energy than the most stable isomer, $\mathrm{NH}_{3} \mathrm{OH}^{+}$. Thus, 265 this value will be the difference of the reaction energies of 266 processes 2 and 1 computed at this level of theory.

Excepting for the formation of the P1 (N-protonated N-268 hydroxyacetamide, $\mathrm{CH}_{3} \mathrm{CONH}_{2}{ }^{+} \mathrm{OH}$ ) and $\mathrm{P} 7$ (O-protonated 269 $\mathrm{N}$-hydroxyacetamidic acid, $\mathrm{CH}_{3} \mathrm{COHNOH}_{2}^{+}$) products from 270 the reaction of $\mathrm{NH}_{3} \mathrm{OH}^{+}$with acetic acid, all reactions studied 271 including those giving protonated glycine are exothermic 272 processes. The most favorable process, from thermodynamic 273 arguments, is the formation of protonated glycine $\left(\mathrm{GlyH}^{+}, 274\right.$ $\mathrm{NH}_{3}{ }^{+} \mathrm{CH}_{2} \mathrm{COOH}$ ). However, the P8 (O-protonated methyl- 275 carbamic acid, $\mathrm{CH}_{3} \mathrm{NHC}(\mathrm{OH})_{2}{ }^{+}$) and the P6 (O-protonated 276 methylcarbamate, $\left.\mathrm{CH}_{3} \mathrm{OC}(\mathrm{OH})^{+} \mathrm{NH}_{2}\right)$ products were found 277 to be very close in energy to the most stable isomer (3.43 and 278 $6.41 \mathrm{kcal} \mathrm{mol}^{-1}$, respectively, at the $\operatorname{CCSD}(\mathrm{T})$ level). The P5 279 (N-protonated glycolamide, $\mathrm{HOCH}_{2} \mathrm{CONH}_{3}{ }^{+}$) product was 280 located $20.28 \mathrm{kcal} \mathrm{mol}^{-1}$ (at the $\operatorname{CCSD}(\mathrm{T}$ ) level) above 281 protonated glycine, and the remaining reaction products were 282 predicted to lie more than $40 \mathrm{kcal} \mathrm{mol}^{-1}$ above protonated 283 glycine.

284

Regardless of the level of theory used, the stability order of 285 the isomers with the $\left[\mathrm{H}_{6} \mathrm{C}_{2} \mathrm{O}_{2} \mathrm{~N}\right]^{+}$molecular formula studied 286 in the present work at the $\operatorname{CCSD}(\mathrm{T}) /$ aug-cc-pVTZ level is 287 (">" means more stable than):

$$
\mathrm{GlyH}^{+}>\mathrm{P} 8>\mathrm{P} 6>\mathrm{P} 5>\mathrm{P} 4>\mathrm{P} 2>\mathrm{P} 3>\mathrm{P} 1>\mathrm{P} 7
$$

If a comparison is made among the results obtained at a 289 different level of theory, we found a stabilization of the P8 and 290 P6 isomers when B3LYP methodology is employed. At this 291 level of theory, protonated glycine and the P8 isomers are 292

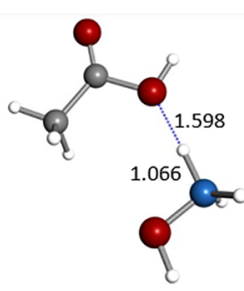

I1P1

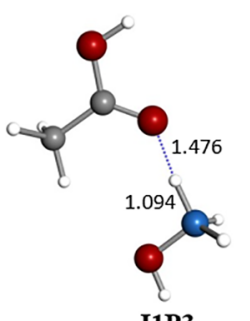

I1P3

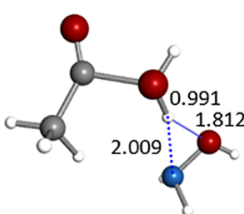

TS1P1

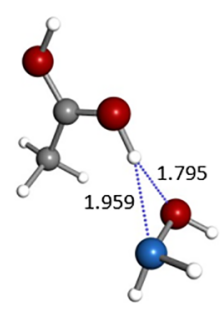

TS1P3

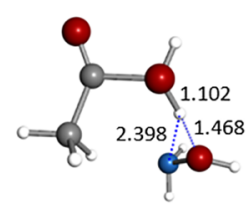

I2P1

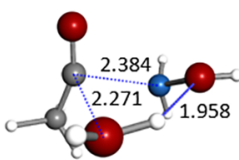

TS2P1

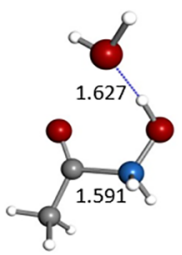

I3P1
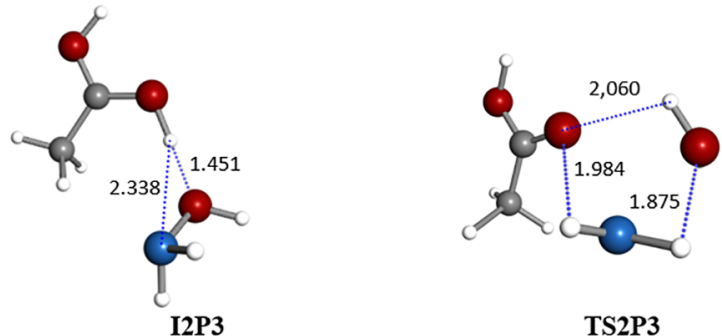

TS2P3

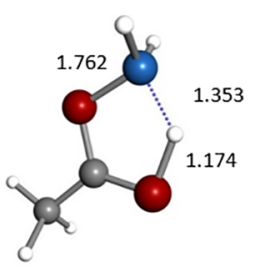

TSIsomer

Figure 2. Intermediates and transition states involved on the reaction of formation of the P1-P3 isomers. Geometries are optimized at the MP2/ aug-cc-pVTZ level of theory. Bond lengths are given in Angstroms. 


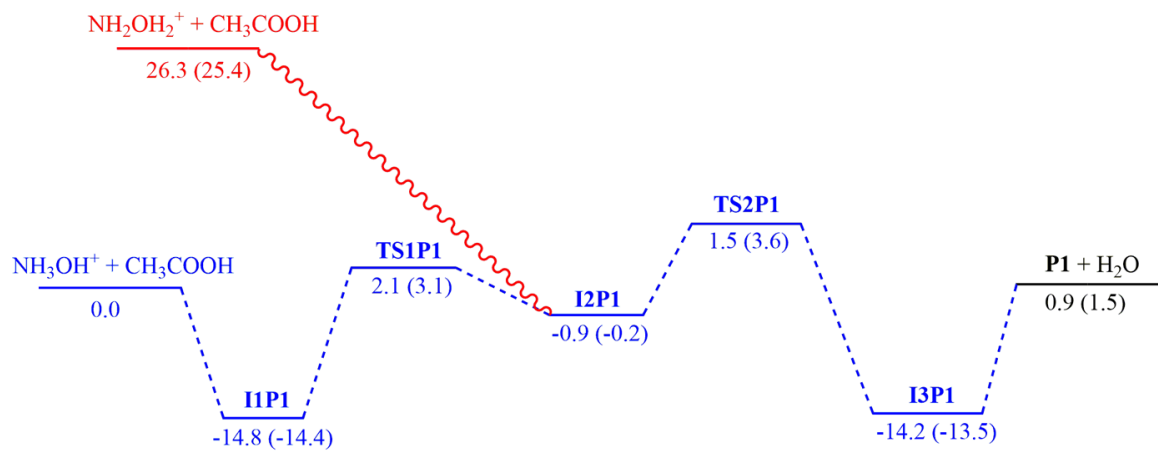

Path a1 $\left(\mathrm{NH}_{3} \mathrm{OH}^{+}\right.$isomer $)$

นกนก Path a2 $\left(\mathrm{NH}_{2} \mathrm{OH}_{2}{ }^{+}\right.$isomer $)$

Figure 3. Energy profile, in $\mathrm{kcal} \mathrm{mol}^{-1}$, for the reactions of protonated hydroxylamine with acetic acid producing P1 computed at the MP2/aug-ccpVTZ and CCSD(T)/aug-cc-pVTZ (in parentheses) levels of theory. Zero-point vibrational energy computed at the MP2/aug-cc-pVTZ level is included.

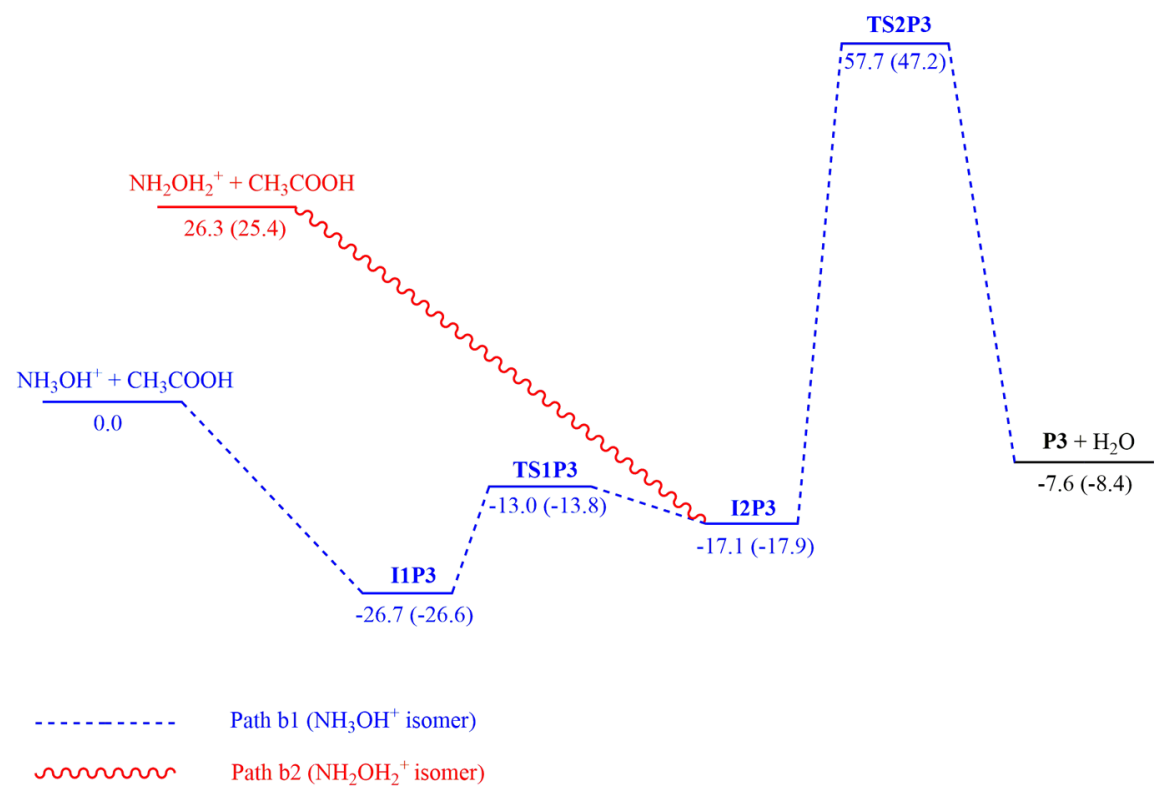

Figure 4. Energy profile, in $\mathrm{kcal} \mathrm{mol}^{-1}$, for the reactions of protonated hydroxylamine with acetic acid producing P3 computed at the MP2/aug-ccpVTZ and CCSD(T)/aug-cc-pVTZ (in parentheses) levels of theory. Zero-point vibrational energy computed at the MP2/aug-cc-pVTZ level is included.

293 almost isoenergetic, with $\mathrm{GlyH}^{+}$being slightly preferred by 0.9 $294 \mathrm{kcal} \mathrm{mol}^{-1}$. On the other hand, the $\operatorname{CCSD}(\mathrm{T})$ level tends to 295 predict lower relative energies than the MP2 one.

296 A large energy difference was found between the two ends of 297 the isomeric system, where protonated glycine, $\mathrm{GlyH}^{+}$(the 298 most stable) and P7 (the less stable) differ by approximately $29970 \mathrm{kcal} \mathrm{mol}^{-1}$. This difference could be expected, and it mainly 300 arises from the different chemical natures of the isomers. The 301 multiple topological dispositions of the 11 atoms that make up 302 the different structures allow one to generate species with 303 different functional groups. In addition, the arrangement of the $304 \mathrm{NH}$ and $\mathrm{OH}$ groups leads to a wide range of possibilities for 305 the formation of intramolecular hydrogen bonds that 306 significantly stabilize this chemical system.

307 The relative stabilities of protonated glycine isomers were 308 previously computed at the B3LYP/6-311G(d,p) level of theory. ${ }^{27}$ From that study, protonated glycine was predicted to 309 be the most stable isomer of the family with the $\mathrm{CH}_{3} \mathrm{NHC}-310$ $(\mathrm{OH})_{2}^{+}(\mathrm{P} 8)$ and the $\mathrm{CH}_{3} \mathrm{OC}(\mathrm{OH})^{+} \mathrm{NH}_{2}$ (P6) isomers 311 located 2.2 and $4.7 \mathrm{kcal} \mathrm{mol}^{-1}$, respectively, higher in energy. 312 Other isomers were found lower in energy than the P5 313 product; however, as it was already mentioned in the 314 introduction, we will focus mainly on the products considered 315 in the chemical dynamics simulations work. ${ }^{26} 316$

Even though protonated glycine is the most stable species 317 among $\left[\mathrm{H}_{6} \mathrm{C}_{2} \mathrm{O}_{2} \mathrm{~N}\right]^{+}$molecular formula species, the chemical 318 dynamics simulations study ${ }^{26}$ of the reaction between 319 protonated hydroxylamine and acetic acid found that P1 and 320 P2 products were the most abundant isomers. It should be 321 noted that these products are located 57.81 and $47.91 \mathrm{kcal} 322$ $\mathrm{mol}^{-1}$, respectively, at the $\operatorname{CCSD}(\mathrm{T})$ level of theory, higher in 323 energy than protonated glycine. Only a small number of P3 324 


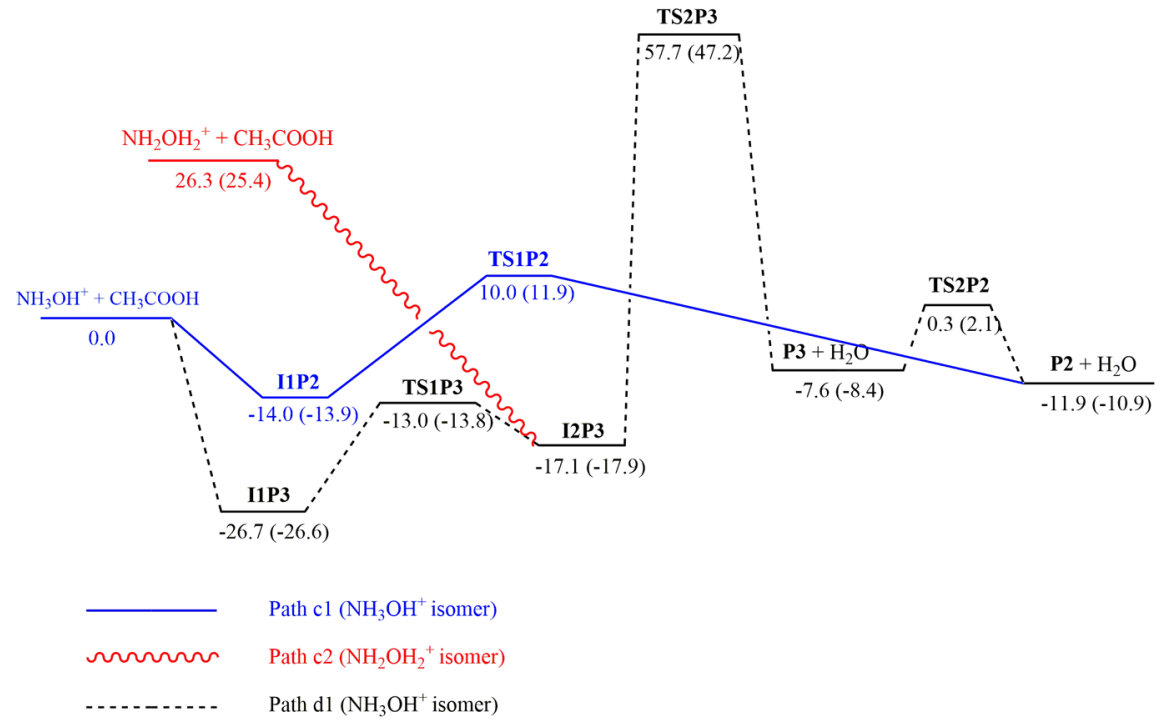

Figure 5. Energy profile, in $\mathrm{kcal} \mathrm{mol}^{-1}$, for the reactions of protonated hydroxylamine with acetic acid producing P2 and P3 computed at the MP2/ aug-cc-pVTZ and CCSD(T)/aug-cc-pVTZ (in parentheses) levels of theory. Zero-point vibrational energy computed at the MP2/aug-cc-pVTZ level is included.

325 and $\mathrm{P} 5$ products were observed at the two temperatures (5 and $326300 \mathrm{~K})$ considered in that work. ${ }^{26}$ Therefore, it should be 327 useful to carry out a full exploration of the PES, to analyze the 328 feasibility of the reactions studied as a source of the P1-P3 329 species in the interstellar medium. Given the conditions of 330 interstellar medium, essentially low temperatures and low 331 densities, interstellar plausible reactions should be exothermic 332 and barrier free processes.

333 Figure 2 depicts the MP2/aug-cc-pVTZ optimized geo334 metries for the intermediate species and transition states, with $335\left[\mathrm{H}_{8} \mathrm{C}_{2} \mathrm{O}_{3} \mathrm{~N}\right]^{+}$molecular formula, involved in the formation 336 process of the $\mathrm{P} 1-\mathrm{P} 3$ isomers. The energy profiles for these 337 reactions computed at MP2 and $\operatorname{CCSD}(\mathrm{T})$ levels of theory are 338 represented in Figures $3-5$. In these representations, the 339 energy of reactants is taken as a reference and the notations $340 \mathrm{I} 1 \mathrm{PX}, \mathrm{I} 2 \mathrm{P} X, \ldots$ and TS1PX, TS2PX, $\ldots(X=1,2,3)$ are used for 341 naming intermediates and transition states, respectively, 342 involved in the corresponding reactions. As can be inferred 343 from the figures, in general, a good agreement between the 344 results obtained with the MP2 and $\operatorname{CCSD}(\mathrm{T})$ methodologies 345 was found.

346 The energy profiles for the reactions of formation of the P1 347 isomer are shown in Figure 3. When the most stable isomer of 348 protonated hydroxylamine, $\mathrm{NH}_{3} \mathrm{OH}^{+}$, is considered, the 349 reaction starts with the formation of the I1P1 intermediate, 350 which is the result of the interaction between the hydroxylic 351 oxygen of acetic acid with one of the hydrogen atoms of the $352 \mathrm{NH}_{3}$ group of protonated hydroxylamine. The exothermic 353 formation of this first intermediate $\left(14.4 \mathrm{kcal} \mathrm{mol}^{-1}\right.$ at the $354 \operatorname{CCSD}(\mathrm{T})$ level) produces an energy reservoir that is used as 355 the reaction proceeds toward the products. Once I1P1 is 356 formed, a hydrogen migration from nitrogen to oxygen takes 357 place through the TS1P1 transition state which is located 3.1 $358 \mathrm{kcal} \mathrm{mol}^{-1}(1560 \mathrm{~K})$ above reactants (at the CCSD $\left.(\mathrm{T})\right)$ level) 359 giving the I2P1 intermediate. This intermediate evolves to the 360 I3P1 intermediate through the TS2P1 transition state which is 361 located, $3.6 \mathrm{kcal} \mathrm{mol}^{-1}(1812 \mathrm{~K})$, at the $\operatorname{CCSD}(\mathrm{T})$ level, above 362 reactants. In the TS2P1 transition state, a water molecule is 363 coordinated to both $\mathrm{NH}_{2} \mathrm{OH}$ and the highly electrophilic ion
$\mathrm{COCH}_{3}{ }^{+}$. Thus, when the $\mathrm{NH}_{2}$ group is properly oriented, a 364 $\mathrm{N}-\mathrm{C}$ bond is formed, giving the I3P1 intermediate. This 365 intermediate finally evolves to the formation of the P1 product 366 and a water molecule. The process can be summarized as 367 follows:

path a1:

$$
\mathrm{NH}_{3} \mathrm{OH}^{+}+\mathrm{CH}_{3} \mathrm{COOH} \rightarrow \mathrm{I} 1 \mathrm{P1} \stackrel{\text { TS1P1 }}{\longrightarrow} \mathrm{I} 2 \mathrm{P} 1 \stackrel{\text { TS2P1 }}{\longrightarrow} \mathrm{I} 3 \mathrm{P} 1 \rightarrow \mathbf{P 1}+\mathrm{H}_{2} \mathrm{O}
$$

As can be seen in Figure 3, the global process is slightly 370 endothermic $\left(\Delta E=1.5 \mathrm{kcal} \mathrm{mol}^{-1}\right.$ at the $\operatorname{CCSD}(\mathrm{T})$ level) and 371 has a small but non-negligible activation barrier of $3.6 \mathrm{kcal} 372$ $\mathrm{mol}^{-1}(1812 \mathrm{~K})$ at the $\operatorname{CCSD}(\mathrm{T})$ level of theory. This barrier 373 precludes this mechanism from taking place in the interstellar 374 medium.

The first step in the mechanism of the formation of the P1 376 product from the less stable isomer of protonated hydroxyl- 377 amine is the direct interaction between one of the hydrogen 378 atoms bonded to oxygen of $\mathrm{NH}_{2} \mathrm{OH}_{2}{ }^{+}$and the hydroxylic 379 oxygen of $\mathrm{CH}_{3} \mathrm{COOH}$ giving the I2P1 intermediate. This 380 complex finally evolves, through TS2P1, to produce P1 and 381 $\mathrm{H}_{2} \mathrm{O}$ as it is schematized in path a2:

path a2:

$$
\mathrm{NH}_{2} \mathrm{OH}_{2}^{+}+\mathrm{CH}_{3} \mathrm{COOH} \rightarrow \mathrm{I} 2 \mathrm{P} 1 \stackrel{\text { TS2P1 }}{\longrightarrow} \mathrm{I} 3 \mathrm{P} 1 \rightarrow \mathbf{P 1}+\mathrm{H}_{2} \mathrm{O}
$$

Pathway a2 is a clearly exothermic process $(\Delta E=-23.9 \mathrm{kcal} 384$ $\mathrm{mol}^{-1}$ at the $\operatorname{CCSD}(\mathrm{T})$ level) with no net activation barrier 385 since now the TS2P1 transition state lies $21.8 \mathrm{kcal} \mathrm{mol}^{-1}$ below 386 reactants. Therefore, the formation of the P1 isomer could be 387 feasible under interstellar conditions from the reaction of the 388 less stable isomer of protonated hydroxylamine and acetic acid. 389

We will consider in advance the analysis of the PES 390 corresponding to the formation of the $\mathrm{P} 3$ isomer because the 391 process of formation of the $\mathrm{P} 2$ isomer can be derived from that 392 of the $\mathrm{P} 3$ product.

Regarding formation of the P3 isomer, depicted in Figure 4, 394 the mechanism of the reaction, involving the most stable 395 isomer of protonated hydroxylamine, starts with the approach 396 of one of the hydrogen atoms bonded to the nitrogen of 397 
$398 \mathrm{NH}_{3} \mathrm{OH}^{+}$to the carbonyl oxygen of acetic acid, giving rise to 399 the I1P3 intermediate. Once I1P3 is obtained, a proton 400 transfer from the $\mathrm{NH}_{3}$ group to the carbonylic oxygen, through 401 the TS1P3 transition state, occurs forming the I2P3 complex. 402 As can be seen from Figure 4, TS1P3 is located lower in energy 403 than the reactants $\left(-13.8 \mathrm{kcal} \mathrm{mol}^{-1}\right.$ at the $\operatorname{CCSD}(\mathrm{T})$ level $)$. 404 From an appropriate spatial arrangement of atoms in the I2P3 405 intermediate, a $\mathrm{N}-\mathrm{O}$ bond cleavage and a simultaneous 406 approach of the $\mathrm{NH}_{2}$ group to the carbonyl oxygen takes place 407 through the TS2P3 transition state which is located $47.2 \mathrm{kcal}$ $408 \mathrm{~mol}^{-1}(23752 \mathrm{~K})$ above reactants (at the $\operatorname{CCSD}(\mathrm{T})$ level). 409 This concerted process will eventually result in the formation 410 of P3. This process can be summarized as

411 path b1:

$$
\mathrm{NH}_{3} \mathrm{OH}^{+}+\mathrm{CH}_{3} \mathrm{COOH} \rightarrow \mathrm{I} 1 \mathrm{P} 3 \stackrel{\mathrm{TS} 1 \mathrm{P} 3}{\longrightarrow} \mathrm{I} 2 \mathrm{P} 3 \stackrel{\text { TS2P3 }}{\longrightarrow} \mathbf{P} 3+\mathrm{H}_{2} \mathrm{O}
$$

412 From this energy profile it seems that production of the P3 413 isomer from the lowest lying isomer of protonated hydroxyl414 amine even though being an exothermic process $(\Delta E=-8.4$ $415 \mathrm{kcal} \mathrm{mol}^{-1}$ at the $\operatorname{CCSD}(\mathrm{T})$ level) involves a large energy 416 barrier $(23752 \mathrm{~K})$, since TS2P3 lies clearly higher in energy 417 than reactants and it will not be feasible under interstellar 418 conditions.

419 When the high-energy isomer of protonated hydroxylamine 420 is considered, the reaction starts with the direct approach of 421 one of the hydrogen atoms bonded to oxygen of $\mathrm{NH}_{2} \mathrm{OH}_{2}{ }^{+}$to 422 the carbonylic oxygen of $\mathrm{CH}_{3} \mathrm{COOH}$ giving the I2P3 423 intermediate. From this intermediate, as in the b1 pathway, 424 the P3 isomer can be obtained from the migration of the $\mathrm{NH}_{2}$ 425 group and subsequent elimination of a water molecule through 426 the TS2P3 transition state. TS2P3 is now located $21.8 \mathrm{kcal}$ $427 \mathrm{~mol}^{-1}(10970 \mathrm{~K})$ above reactants at the $\operatorname{CCSD}(\mathrm{T})$ level. The 428 process can be represented as

429 path b2:

$$
\mathrm{NH}_{2} \mathrm{OH}_{2}{ }^{+}+\mathrm{CH}_{3} \mathrm{COOH} \rightarrow \mathrm{I} 2 \mathrm{P} 3 \stackrel{\text { TS2P3 }}{\longrightarrow} \mathbf{P} 3+\mathrm{H}_{2} \mathrm{O}
$$

430 Therefore, the formation of the P3 isomer from the reaction 431 of the less stable isomer of protonated glycine and acetic acid is 432 an exothermic process $\left(\Delta E=-33.8 \mathrm{kcal} \mathrm{mol}^{-1}\right)$; however, a 433 net activation barrier of $21.8 \mathrm{kcal} \mathrm{mol}^{-1}$ was found, and this 434 process will not be allowed under interstellar conditions.

435 It should be noted that the PES for the P3 isomer was 436 previously studied ${ }^{44}$ in an experimental and theoretical work 437 using the CBS-QB3 complete basis set model chemistry. ${ }^{45}$ 438 From that study, the existence of a relationship with 439 glycolaldehyde through a dissociative process is suggested.

440 In Figure 5 the PES corresponding to the formation of the $441 \mathrm{P} 2$ isomer from the two isomers of protonated hydroxylamine 442 is schematized. If the reaction is initiated from $\mathrm{NH}_{3} \mathrm{OH}^{+}$, the 443 mechanism starts with a concerted approach between both one 444 of the hydrogen atoms bonded to nitrogen and the hydroxylic 445 hydrogen of $\mathrm{NH}_{3} \mathrm{OH}^{+}$to the hydroxylic oxygen of $\mathrm{CH}_{3} \mathrm{COOH}$ 446 giving the I1P2 intermediate. This intermediate evolves toward 447 the products formation $\left(\mathrm{P} 2+\mathrm{H}_{2} \mathrm{O}\right)$ through the TS1P2 448 transition state. In this transition state, the hydrogen atom of 449 the hydroxyl group of $\mathrm{NH}_{3} \mathrm{OH}^{+}$is transferred to the hydroxylic 450 oxygen of $\mathrm{CH}_{3} \mathrm{COOH}$, preforming a water molecule. 451 Simultaneously, the highly reactive oxygen atom of the $452 \mathrm{NH}_{3} \mathrm{O}$ group interacts with the carbonyl carbon atom of 453 acetic acid generating the $\mathrm{P} 2$ product in a concerted process where a water molecule is released. The process can be 454 schematized as follows:

path c1:

$$
\mathrm{NH}_{3} \mathrm{OH}^{+}+\mathrm{CH}_{3} \mathrm{COOH} \rightarrow \mathrm{I} 1 \mathrm{P} 2 \stackrel{\mathrm{TS} 1 \mathrm{P} 2}{\longrightarrow} \mathbf{P 2}+\mathrm{H}_{2} \mathrm{O} \quad \text { (c1) }{ }_{457}
$$

As can be seen from Figure 5, the reaction of formation of 458 the P2 isomer, from the lowest lying isomer of protonated 459 hydroxylamine through the cl pathway, is an exothermic 460 process $\left(\Delta E=-10.9 \mathrm{kcal} \mathrm{mol}^{-1}\right.$ at the $\operatorname{CCSD}(\mathrm{T})$ level $)$ that 461 involves a significant energy barrier since TS1P2 lies $11.9 \mathrm{kcal} 462$ $\mathrm{mol}^{-1}$ (at the $\operatorname{CCSD}(\mathrm{T})$ level) than the reactants.

463

If we compare the $\mathrm{b} 1$ and $\mathrm{cl}$ pathways, it can be seen that in 464 the former additional energy is required to release the 465 hydroxylic hydrogen of $\mathrm{NH}_{3} \mathrm{OH}^{+}$, whereas in the latter 466 pathway a most favorable proton transfer occurs. This energy 467 difference correlates with the energy associated with the 468 following two processes: ${ }^{26}$

$$
\begin{aligned}
& \mathrm{NH}_{3} \mathrm{OH}^{+} \rightarrow \mathrm{NH}_{3} \mathrm{O}+\mathrm{H}^{+} \\
& \quad\left(\Delta E=211.6 \mathrm{kcal} \mathrm{mol}^{-1} \text { at the MP2 } / \text { aug-cc-pVTZ level }\right) \\
& \mathrm{NH}_{3} \mathrm{OH}^{+} \rightarrow \mathrm{NH}_{2} \mathrm{OH}+\mathrm{H}^{+} \\
& \quad\left(\Delta E=186.0 \mathrm{kcal} \mathrm{mol}^{-1} \text { at the MP2 } / \text { aug-cc-pVTZ level }\right)
\end{aligned}
$$

Another possibility for obtaining the P2 isomer, from 470 $\mathrm{NH}_{3} \mathrm{OH}^{+}$, implies, first, the formation of the $\mathrm{P} 3$ product 471 through the b1 pathway. Once P3 is obtained, second, the 472 hydrogen atom migration from the oxygen atom to the 473 nitrogen one, through the TS2P2 transition state, leads to the 474 most stable isomer P2. This P3 $\rightarrow$ P2 isomerization process 475 implies an energy barrier of $10.5 \mathrm{kcal} \mathrm{mol}^{-1}$ (at the $\operatorname{CCSD}(\mathrm{T}) 476$ level). The overall process can be summarized as 477 path d1:

$$
\begin{aligned}
& \mathrm{NH}_{3} \mathrm{OH}^{+}+\mathrm{CH}_{3} \mathrm{COOH} \rightarrow \mathrm{I} 1 \mathrm{P} 3 \stackrel{\mathrm{TS} 1 \mathrm{P} 3}{\longrightarrow} \mathrm{I} 2 \mathrm{P} 3 \stackrel{\mathrm{TS} 2 \mathrm{P} 3}{\longrightarrow} \mathbf{P} 3+\mathrm{H}_{2} \mathrm{O} \\
& \stackrel{\mathrm{TS} 2 \mathrm{P} 2}{\longrightarrow} \mathbf{P 2}+\mathrm{H}_{2} \mathrm{O}
\end{aligned}
$$

The TS2P2 transition state is located $2.1 \mathrm{kcal} \mathrm{mol}^{-1}$ higher 479 in energy than reactants, and production of the P3 isomer 480 involves a large energy barrier $(23752 \mathrm{~K})$; thus, the $\mathrm{d} 1$ path 481 will have the same characteristics as the cl pathway. 482

The reaction of formation of the P2 product from the 483 highest energy isomer of protonated hydroxylamine starts with 484 the interaction between one of the hydrogen atoms bonded to 485 nitrogen in $\mathrm{NH}_{2} \mathrm{OH}_{2}{ }^{+}$and the carbonylic oxygen of acetic acid 486 giving the I2P3 intermediate. This complex, following the b1 487 pathway, evolves to the $\mathrm{P} 3$ product, and then it isomerizes into 488 the most stable P2 product through the TS2P2 transition state: 489 path c2:

$$
\mathrm{NH}_{2} \mathrm{OH}_{2}^{+}+\mathrm{CH}_{3} \mathrm{COOH} \rightarrow \mathrm{I} 2 \mathrm{P} 3 \stackrel{\text { TS2P3 }}{\longrightarrow} \mathbf{P 3}+\mathrm{H}_{2} \mathrm{O} \stackrel{\text { TS2P2 }}{\longrightarrow} \mathbf{P 2}+\mathrm{H}_{2} \mathrm{O}
$$

The process represented by the c2 pathway is clearly 492 exothermic $\left(\Delta E=-36.3 \mathrm{kcal} \mathrm{mol}^{-1}\right.$ at the $\operatorname{CCSD}(\mathrm{T})$ level $) 493$ but has a significant activation barrier $\left(21.8 \mathrm{kcal} \mathrm{mol}^{-1}\right.$ at the 494 $\operatorname{CCSD}(\mathrm{T})$ level), and consequently it should not be relevant 495 under interstellar conditions.

Our results show that the formation of $\mathrm{P} 1,497$ $\mathrm{CH}_{3} \mathrm{CONH}_{2}{ }^{+} \mathrm{OH}$, is the only favorable product from this 498 reaction. It should be noted that protonated complex organic 499 molecules (COMs) have not been yet detected in ISM; it 500 
Table 2. Spectroscopic Parameters for the P1-P8 Isomers Computed at the MP2/aug-cc-pVTZ Level of theory

\begin{tabular}{|c|c|c|c|c|c|c|c|c|}
\hline param & P1 & P2 & P3 & P4 & P5 & P6 & P7 & P8 \\
\hline$A^{a}$ & 9767 & 10218 & 10478 & 10161 & 8524 & 9996 & 10140 & 10290 \\
\hline$B$ & 3858 & 4126 & 4162 & 4027 & 4192 & 4280 & 4043 & 4054 \\
\hline C & 2859 & 3045 & 3085 & 2961 & 2906 & 3057 & 2957 & 29638 \\
\hline$A_{0}^{b}$ & 9652 & 10173 & 10419 & 10087 & 8423 & 9907 & 10046 & 10188 \\
\hline$B_{0}$ & 3799 & 4086 & 4141 & 4000 & 4174 & 4230 & 4008 & 4020 \\
\hline$C_{0}$ & 2819 & 3021 & 3068 & 2938 & 2896 & 3023 & 2930 & 2937 \\
\hline$\Delta_{J}^{c}$ & 0.90 & 0.72 & 0.61 & 0.60 & 0.72 & 0.77 & 0.64 & 0.68 \\
\hline$\Delta_{K}$ & 7.78 & 5.35 & 4.78 & 6.38 & -27.02 & 2.02 & 6.57 & 2.00 \\
\hline$\Delta_{J K}$ & 2.11 & 4.37 & 5.23 & 3.88 & 34.59 & 3.67 & 3.24 & 4.87 \\
\hline$\delta_{J}$ & 0.23 & 0.19 & 0.16 & 0.16 & 0.18 & 0.22 & 0.16 & 0.18 \\
\hline$\delta_{K}$ & 0.98 & -5.66 & -4.16 & 2.13 & -14.68 & 2.74 & 2.06 & 2.17 \\
\hline $\mathrm{X}_{a}^{d}$ & 1.60 & 0.26 & 5.40 & -1.20 & -0.43 & 1.02 & 6.10 & 2.04 \\
\hline$X_{b}-X_{c}$ & 1.10 & 0.35 & -3.44 & 1.79 & -0.10 & 5.51 & 0.05 & 4.40 \\
\hline$\left|\mu_{a}\right| /\left|\mu_{b}\right| /\left|\mu_{c}\right|^{e}$ & $1.4 / 3.8 / 0.0$ & $4.7 / 1.4 / 0.0$ & $1.5 / 0.7 / 0.0$ & $0.7 / 2.1 / 1.1$ & $1.3 / 3.2 / 0.1$ & $0.8 / 1.7 / 0.0$ & $1.4 / 1.8 / 1.5$ & $1.4 / 0.4 / 0.0$ \\
\hline$P_{c}^{f}$ & 3.046 & 3.020 & 2.919 & 2.208 & 3.84 & 1.655 & 1.957 & 1.624 \\
\hline
\end{tabular}

${ }^{a} A, B$, and $C$ represent the rotational constants of the equilibrium structure (in $\mathrm{MHz}$ ). ${ }^{b} A_{0}, B_{0}$, and $C_{0}$ are the rotational constants of the ground vibrational state, $v=0$ (in $\mathrm{MHz}) .{ }^{c} \Delta_{J}, \Delta_{K}, \Delta_{I K}, \delta_{J}$, and $\delta_{K}$ represent the quartic centrifugal distortion constants (in $\mathrm{kHz}$ ). ${ }^{d} \mathrm{X}_{a}, \mathrm{X}_{b}$, and $\mathrm{X}_{c}$ represent the elements of the ${ }^{14} \mathrm{~N}$ nuclear quadrupole coupling tensor (in $\mathrm{MHz}$ ). ${ }^{e}\left|\mu_{c}\right|$ are the absolute values of the electric dipole-moment components (in D). ${ }^{f} P_{\mathrm{c}}$ is the planar inertial moment (in $\mathrm{u} \mathrm{A}^{2}$ ). Conversion factor: $505379.1 \mathrm{MHz}^{-1} \mathrm{u} \mathrm{A}^{2}$.

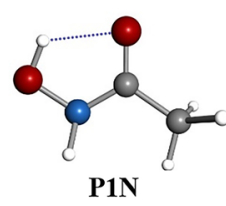

N-hydroxyacetamide $\mathrm{CH}_{3} \mathrm{CONHOH}$

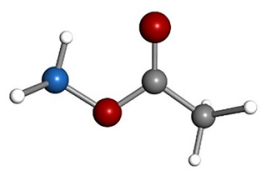

P2N

O-Acetylhydroxylamine $\mathrm{CH}_{3} \mathrm{COONH}_{2}$

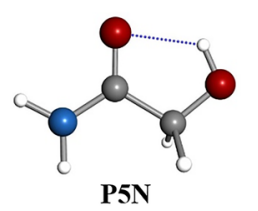

Glycolamide

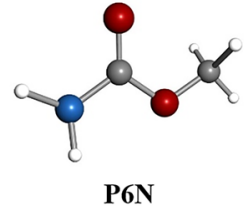

Methylcarbamate

$\mathrm{CH}_{3} \mathrm{OCONH}_{2}$

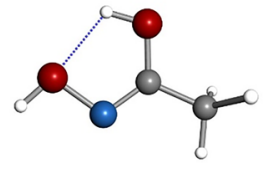

P7N

N-Hydroxyacetamidic acid

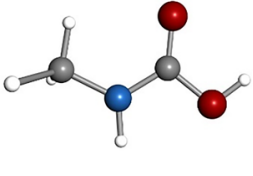

P8N

Methylcarbamic acid

$\mathrm{CH}_{3} \mathrm{NHCOOH}$

Figure 6. Chemical Structures of $\left[\mathrm{H}_{5} \mathrm{C}_{2} \mathrm{O}_{2} \mathrm{~N}\right]$ isomers optimized at MP2/aug-cc-pVTZ level of theory

501 seems that they could evolve to neutral species by dissociative 502 recombination. Therefore, the neutral isomer, $\mathrm{OHNHCOCH}_{3}$, 503 might be a candidate molecule to be searched for in the 504 interstellar medium.

505 3.2. Structure and Spectroscopic Parameters of $506\left[\mathrm{H}_{6} \mathrm{C}_{2} \mathrm{O}_{2} \mathrm{~N}\right]^{+}$and $\left[\mathrm{H}_{5} \mathrm{C}_{2} \mathrm{O}_{2} \mathrm{~N}\right]$ Isomers. Structural data for 507 the $\left[\mathrm{H}_{6} \mathrm{C}_{2} \mathrm{O}_{2} \mathrm{~N}\right]^{+}$isomers are given as Supporting Information, 508 in Table S1. In Table 2, we provide the relevant spectroscopic 509 parameters to rotational spectroscopy, together with computed 510 dipole-moment components along their principal inertial axes, 511 for the P1-P8 isomers. Equilibrium rotational constants $(A, B$, $512 C$ ) were computed at the MP2/aug-cc-pVTZ level, and the 513 corresponding rotational constants for the ground vibrational 514 state were calculated from vibration-rotation coupling 515 constants and degeneracy factors for the vibrational modes. 516 We have also included in the table centrifugal distortion 517 parameters in the symmetrically reduced Hamiltonian $\left(\Delta_{J}, \Delta_{K}\right.$, $518 \Delta_{J K}, \delta_{J}$, and $\left.\delta_{K}\right) \cdot\left[\mathrm{H}_{6} \mathrm{C}_{2} \mathrm{O}_{2} \mathrm{~N}\right]^{+}$isomers possess one nucleus 519 with the quadrupole moment, ${ }^{14} \mathrm{~N}(I=1)$. The interaction at 520 the nucleus of this quadrupole moment with the electric field 521 gradient created by the rest of the molecular charges causes the 522 coupling of the nuclear spin moments to the overall rotational momentum. Hence, each rotational transition of P1-P8 523 isomers carries the nuclear quadrupole hyperfine pattern 524 expected for the presence of the ${ }^{14} \mathrm{~N}$ nucleus, giving rise to a 525 complex hyperfine pattern. Thus, in Table 2, the elements of 526 the ${ }^{14} \mathrm{~N}$ nuclear quadrupole coupling tensor $\left(\mathrm{X}_{a}, \mathrm{X}_{b}\right.$, and $\left.\mathrm{X}_{c}\right){ }_{527}$ are given.

Planar moments of inertia, $P_{c}$, have been also included in 529 Table 2. They can be obtained from rotational constants 530 through the relation $P_{c}=h /\left(16 \pi^{2}\right)\left(-1 / A_{0}+1 / \mathrm{B}<_{0}+1 / C_{0}\right) 531$ and represent the mass distribution outside the $a b$ inertial 532 plane. As can be seen in Table 2, the planar moments for the 533 P1-P8 isomers are, in all cases, relatively significant in 534 magnitude and different from zero indicating that all P1-P8 535 isomers are not entirely rigid nor planar structures. On the 536 other hand, the values of the computed dipole moments are 537 high enough to allow for the observation of their 538 corresponding rotational spectra using standard micro- and 539 millimeter-wave spectroscopy instruments.

540

All reaction products were predicted to be asymmetric tops. 541 This characteristic together with the presence of one ${ }^{14} \mathrm{~N} 542$ nucleus with a quadrupole moment $(I=1)$ results in a complex 543 rotational spectrum. 
545 To help in the possible identification of P1-P8 isomers in 546 the gas phase through IR spectroscopy, in Table S2 of the 547 Supporting Information, we give their predicted MP2/aug-cc548 pVTZ harmonic and anharmonic vibrational frequencies. For 549 all of the P1-P8 isomers, anharmonic frequencies are lower 550 than the corresponding harmonic ones and the largest 551 differences between harmonic and anharmonic frequencies 552 were found, in general, in the frequencies corresponding to 553 stretching modes.

554 Once P1-P8 ionic species were studied, the next step was to 555 obtain spectroscopic information for the corresponding neutral 556 species denoted as $\mathrm{P} 1 \mathrm{~N}-\mathrm{P} 8 \mathrm{~N}$. All of them are structural 557 isomers of glycine and have $\left[\mathrm{H}_{5} \mathrm{C}_{2} \mathrm{O}_{2} \mathrm{~N}\right]$ molecular formula. In 558 this case, six different chemical species were analyzed, since 559 both the $\mathrm{P} 1 \mathrm{~N}$ and $\mathrm{P} 4 \mathrm{~N}$ isomers and the $\mathrm{P} 2 \mathrm{~N}$ and $\mathrm{P} 3 \mathrm{~N}$ isomers 560 converge, respectively, in the same neutral species $(\mathrm{P} 1 \mathrm{~N}=$ $561 \mathrm{P} 4 \mathrm{~N}, \mathrm{P} 2 \mathrm{~N}=\mathrm{P} 3 \mathrm{~N}$ ). The six isomeric species studied together 562 with neutral glycine are presented in Figure 6.

563 Again, for each isomer a previous conformational analysis 564 was performed. In Table 3, the relative energies for the most

Table 3. Relative Energies, Including Zero Point Corrections, in $\mathrm{kcal} \mathrm{mol}^{-1}$, for Glycine (Gly) and Its Structural Isomers

$\begin{array}{crrrc}\text { isomer } & \text { B3LYP }^{a} & \mathrm{MP2}^{b} & \mathrm{CCSD}^{c} & \mathrm{CCSD}^{c}(\mathrm{~T})^{d} \\ \text { P8N } & 0.00 & 0.00 & 0.00 & 0.00 \\ \text { P6N } & 4.29 & 5.26 & 4.64 & 4.64 \\ \text { Gly } & 10.44 & 9.05 & 8.98 & 8.44 \\ \text { P5N } & 11.02 & 10.16 & 9.92 & 9.67 \\ \text { P2N } & 43.51 & 46.36 & 44.96 & 43.47 \\ \text { P1N } & 44.32 & 46.77 & 46.03 & 44.66 \\ \text { P7N } & 47.30 & 48.23 & 46.94 & 45.45\end{array}$

${ }^{a}$ Electronic energy calculated at the B3LYP/cc-pVTZ. ${ }^{b}$ Electronic energy calculated at the MP2/aug-cc-pVTZ levels. ${ }^{c}$ Electronic energy calculated at the CCSD/aug-cc-pVTZ//MP2/aug-cc-pVTZ level. ${ }^{d}$ Electronic energy calculated at the $\operatorname{CCSD}(\mathrm{T}) /$ aug-cc-pVTZ// MP2/aug-cc-pVTZ level.

565 stable conformers of the $\left[\mathrm{H}_{5} \mathrm{C}_{2} \mathrm{O}_{2} \mathrm{~N}\right]$ isomers obtained at 566 different levels of theory are given. As can be observed from 567 the table, the stability order is not modified when going from 568 the B3LYP level to the $\operatorname{CCSD}(\mathrm{T})$ one. The most stable 569 structure is the $\mathrm{P} 8 \mathrm{~N}$ isomer ( $\mathrm{N}$-methylcarbamic acid, $570 \mathrm{CH}_{3} \mathrm{NHCOOH}$ ) and the less stable one corresponds to the $571 \mathrm{P} 7 \mathrm{~N}$ structure ( $\mathrm{N}$-hydroxyacetamidic acid, $\mathrm{CH}_{3} \mathrm{COHNOH}$ ). It 572 should be noted that, among neutral isomers, glycine (Gly) is 573 not the most stable species; it is situated in stability between 574 P6N (methylcarbamate, $\mathrm{CH}_{3} \mathrm{OCONH}_{2}$ ) and $\mathrm{P5N}$ (glyco575 lamide, $\mathrm{HOCH}_{2} \mathrm{CONH}_{2}$ ) isomers. Regardless of the level of 576 calculation employed, the stability order of the isomers 577 considered in this work with $\left[\mathrm{H}_{5} \mathrm{C}_{2} \mathrm{O}_{2} \mathrm{~N}\right]$ molecular formula 578 is (">" means more stable than):

$$
\text { P8N }>\text { P6N }>\text { Gly }>\text { P5N }>\text { P2N }>\text { P1N }>\text { P7N }
$$

579 The energetic difference between the ends of the series is 580 now lower than in the protonated counterpart. The high581 energy isomer, $\mathrm{P} 7 \mathrm{~N}$, is $45.5 \mathrm{kcal} \mathrm{mol}^{-1}$ (at the $\operatorname{CCSD}(\mathrm{T})$ level) 582 higher in energy than the most stable one P8N.

583 Lattelais et al. ${ }^{27}$ in their study of the isomers of glycine 584 found that the most stable isomer was not glycine, but $\mathrm{N}$ 585 methylcarbamic acid (P8N). Following in energy were found 586 methylcarbamate (P6N) and glycine (Gly), which are located
4.9 and $8.8 \mathrm{kcal} \mathrm{mol}^{-1}$, respectively, higher in energy than the 587 most stable isomer at the $\operatorname{CCSD}(\mathrm{T}) / \mathrm{cc}-\mathrm{pVQZ} / / \mathrm{B} 3 \mathrm{LYP} / 6-588$ $311 \mathrm{G}(\mathrm{d} . \mathrm{p})$ level.

Proton transfer processes are common in the interstellar 590 medium; therefore, we have computed proton affinities for the 591 neutral isomers, which are showen, at different level of theory, 592 in Table 4. As can be seen from the table, the values of proton $593 \mathrm{t} 4$

Table 4. Proton Affinities, Including Zero Point Corrections, in $\mathrm{kcal} \mathrm{mol}^{-1}$, for $\left[\mathrm{H}_{5} \mathrm{C}_{2} \mathrm{O}_{2} \mathrm{~N}\right]$ Isomers

$\begin{array}{ccccc}\text { reacn } & \text { B3LYP }^{a} & \text { MP2 }^{b} & \text { CCSD }^{c} & {\text { CCSD }(T)^{d}}^{d} \\ \text { P8N + H } \rightarrow \text { P8 } & 201.37 & 196.44 & 200.67 & 199.15 \\ \text { P6N + H } \rightarrow \text { P6 } & 203.35 & 198.22 & 202.35 & 200.80 \\ \text { P5N + H } \rightarrow \text { P5 } & 192.60 & 189.87 & 192.69 & 191.97 \\ \text { P2N + H } \rightarrow \text { P2 } & 202.66 & 199.80 & 201.66 & 200.71 \\ \text { P2N + H } \rightarrow \text { P3b } & 200.67 & 195.53 & 199.59 & 198.14 \\ \text { P1N + H } \rightarrow \text { P 4d } & 206.31 & 201.12 & 205.89 & 203.78 \\ \text { P1N + H } \rightarrow \text { P1b } & 189.40 & 187.46 & 190.33 & 189.43 \\ \text { P7N + H } \rightarrow \text { P7a } & 181.95 & 175.21 & 180.86 & 178.45\end{array}$

${ }^{a}$ Electronic energy calculated at the B3LYP/cc-pVTZ. ${ }^{b}$ Electronic energy calculated at the MP2/aug-cc-pVTZ levels. ${ }^{c}$ Electronic energy calculated at the CCSD/aug-cc-pVTZ//MP2/aug-cc-pVTZ level. ${ }^{d}$ Electronic energy calculated at the $\operatorname{CCSD}(\mathrm{T}) /$ aug-cc-pVTZ// MP2/aug-cc-pVTZ level.

affinities are relatively high if comparison is made to those of 594 some abundant interstellar molecules. For example, the proton 595 affinities of $\mathrm{H}_{2}, \mathrm{CO}$, and $\mathrm{C}_{2} \mathrm{H}_{2}$ are 100,143 , and $152 \mathrm{kcal} 596$ $\mathrm{mol}^{-1}$, respectively. Therefore, neutral isomers should react 597 quite easily in proton-rich interstellar media to give the 598 corresponding protonated species.

599

As it was noted for the protonated systems, other isomers 600 were found lower in energy than the P5N product, in the 601 theoretical study of Lattelais et al. ${ }^{27}$ However, we will only 602 provide spectroscopic information for the neutral isomers 603 derived from the products considered in the chemical 604 dynamics simulations work. $^{26} \quad 605$

As Supporting Information, in Table S3, we give geometrical 606 parameters for the $\left[\mathrm{H}_{5} \mathrm{C}_{2} \mathrm{O}_{2} \mathrm{~N}\right]$ isomers.

Rotational spectroscopic parameters for neutral isomers are 608 given in Table 5. As in their protonated counterparts, all 609 t5 neutral isomers are asymmetric tops and their rotational 610 spectrum should show the quadrupole hyperfine pattern that 611 can be expected for those of molecules with a ${ }^{14} \mathrm{~N}$ atom. Dipole 612 moments values for the neutral isomers were high enough to 613 allow for their characterization by micro- and millimeter-wave 614 spectroscopy.

615

According to our calculations $N$-hydroxyacetamide (P1N), 616 the neutral counterpart of the only protonated isomer which 617 could be formed from the reaction of acetic acid and 618 protonated hydroxylamine under interstellar conditions is an 619 asymmetric rotor. In Figure 7, we present a prediction of the $620 \mathrm{f} 7$ rotational spectra ${ }^{46}$ in a large spectral range interesting for 621 astrophysical use $(40-200 \mathrm{GHz})$. Its rotational spectrum can 622 be derived from the corresponding rotational constants and 623 dipole-moment components in order to guide spectral 624 searches. ${ }^{14} \mathrm{~N}$ nuclear quadrupole coupling tensor constants 625 are also included in the predictions. This study, in combination 626 with a plausible frequency modulation millimeter-wave 627 spectroscopic work, should allow astrophysicists to search for 628 $N$-hydroxyacetamide in the ISM using the available survey data 629 from IRAM 30m, ARO, CARMA, ALMA, .... 
Table 5. Spectroscopic Parameters for the $\left[\mathrm{H}_{5} \mathrm{C}_{2} \mathrm{O}_{2} \mathrm{~N}\right]$ Isomers Computed at the MP2/aug-cc-pVTZ Level of theory

\begin{tabular}{|c|c|c|c|c|c|c|}
\hline param & $\mathrm{P} 1 \mathrm{~N}$ & $\mathrm{P} 2 \mathrm{~N}$ & P5N & P6N & P7N & P8N \\
\hline$A^{a}$ & 10600 & 10465 & 10449 & 10673 & 10114 & 10695 \\
\hline$B$ & 4140 & 4236 & 4077 & 4429 & 4133 & 4109 \\
\hline$C$ & 3045 & 3102 & 2987 & 3196 & 2988 & 3025 \\
\hline$A_{0}{ }^{b}$ & 10529 & 10383 & 10361 & 10593 & 10012 & 10625 \\
\hline$B_{0}$ & 4099 & 4193 & 4015 & 4389 & 411 & 4063 \\
\hline$C_{0}$ & 3015 & 3073 & 2955 & 3164 & 2962 & 2989 \\
\hline$\Delta_{J}^{c}$ & 0.72 & 0.76 & 0.76 & 0.77 & 0.67 & 0.65 \\
\hline$\Delta_{K}$ & 7.73 & 6.66 & 2.29 & 3.83 & 5.80 & -5.15 \\
\hline$\Delta_{J K}$ & 3.22 & 4.14 & 6.31 & 3.05 & 5.21 & 12.65 \\
\hline$\delta_{J}$ & 0.19 & 0.21 & 0.20 & 0.21 & 0.17 & 0.17 \\
\hline$\delta_{K}$ & 1.62 & -0.29 & 2.050 & 2.39 & 3.16 & -16.2 \\
\hline $\mathrm{X}_{a}^{d}$ & 4.04 & 4.39 & 5.93 & 2.21 & 5.06 & 2.55 \\
\hline$X_{b}-X_{c}$ & 5.70 & 3.83 & 0.09 & 6.07 & -3.55 & 6.59 \\
\hline$\left|\mu_{a}\right| /\left|\mu_{b}\right| /\left|\mu_{c}\right|^{e}$ & $1.7 / 2.7 / 0.8$ & $0.8 / 1.1 / 1.3$ & $3.2 / 3.0 / 0.0$ & $0.1 / 2.2 / 0.6$ & $2.5 / 0.0 / 0.0$ & $1.2 / 2.2 / 0.0$ \\
\hline$P_{c}^{f}$ & 1.835 & 2.373 & 1.812 & 1.564 & 1.365 & 1.436 \\
\hline
\end{tabular}

${ }^{a} A, B$, and $C$ represent the rotational constants of the equilibrium structure (in $\mathrm{MHz}$ ). ${ }^{b} A_{0}, B_{0}$, and $C_{0}$ are the rotational constants of the ground vibrational state, $\mathrm{v}=0$ (in $\mathrm{MHz}) .{ }^{c} \Delta_{J}, \Delta_{K}, \Delta_{J K}, \delta_{J}$, and $\delta_{K}$ represent the quartic centrifugal distortion constants (in $\mathrm{kHz}$ ). ${ }^{d} \mathrm{X}_{a}, \mathrm{X}_{b}$, andX $\mathrm{X}_{c}$ represent the elements of the ${ }^{14} \mathrm{~N}$ nuclear quadrupole coupling tensor (in $\mathrm{MHz}$ ). ${ }^{e}\left|\mu_{a}\right|,\left|\mu_{b}\right|$, and $\left|\mu_{c}\right|$ are the absolute values of the electric dipole-moment components (in D). ${ }^{{ }} P_{c}$ is the planar inertial moment (in $\mathrm{u} \mathrm{A}^{2}$ ). Conversion factor: $505379.1 \mathrm{MHz}^{-1} \mathrm{u} \mathrm{A}^{2}$.
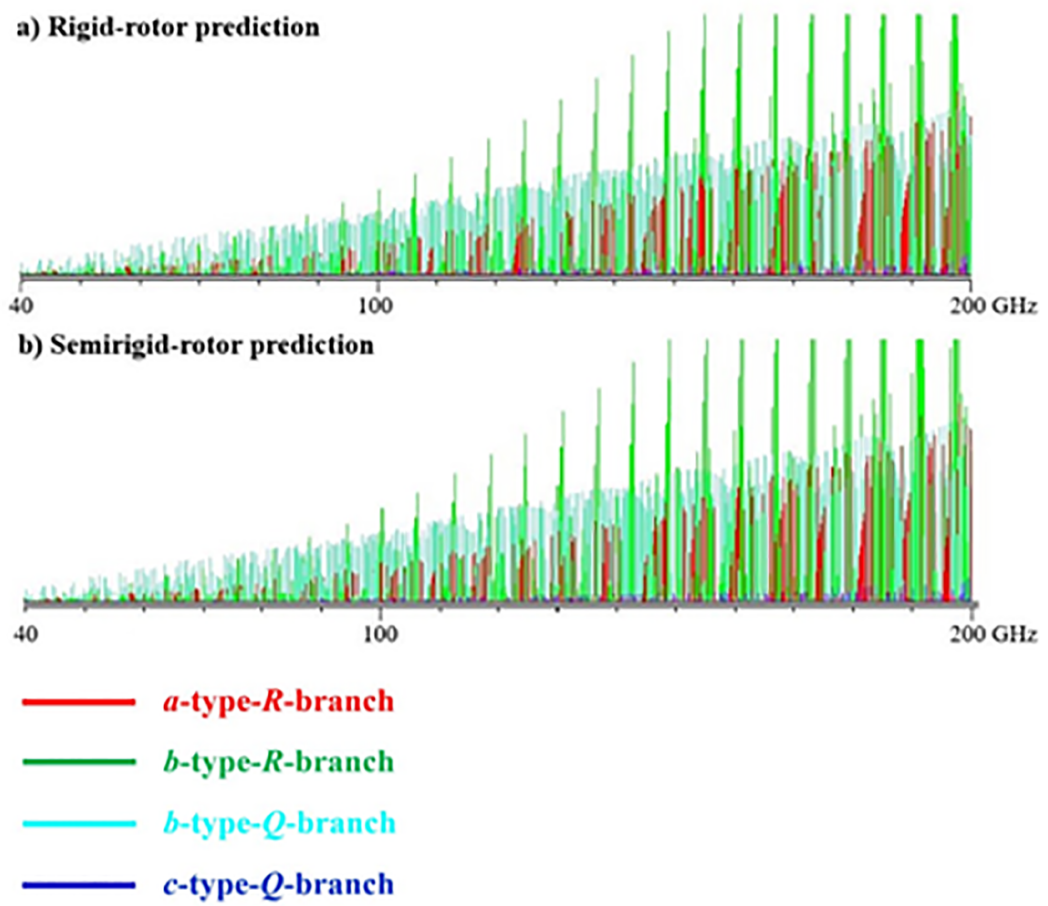

Figure 7. Calculated rotational spectra of $\mathrm{N}$-Hydroxyacetamide (P1N) at room temperature. a) Rotational spectrum in the 40-200 GHz frequency region using a rigid-rotor approximation. b) Rotational spectrum in the $40-200 \mathrm{GHz}$ frequency region using a semirigid-rotor approximation including quartic centrifugal distortion parameters in the symmetrically reduced Hamiltonian. SPCAT program ${ }^{46}$ is used to predict frequencies and intensities from the parameters.

631 Finally, the calculated harmonic and anharmonic vibrational 632 frequencies and IR intensities for the neutral isomers are given 633 in Table S4 as Supporting Information. This information could 634 be useful for their eventual detection in the gas phase through 635 IR spectroscopy.

\section{CONCLUSION}

636 In this work, we have carried out a theoretical study of the 637 possible products obtained from reaction between protonated 638 hydroxylamine and acetic acid. These products have $639\left[\mathrm{H}_{6} \mathrm{C}_{2} \mathrm{O}_{2} \mathrm{~N}\right]^{+}$molecular formula and are structural isomers of protonated glycine. In addition, their neutral counterparts, with 640 $\left[\mathrm{H}_{5} \mathrm{C}_{2} \mathrm{O}_{2} \mathrm{~N}\right]$ molecular formula have been analyzed. 641

For the $\left[\mathrm{H}_{6} \mathrm{C}_{2} \mathrm{O}_{2} \mathrm{~N}\right]^{+}$system, all levels of theory employed in 642 this study predict protonated glycine as the lowest energy 643 isomer with the P8 $\left(\mathrm{CH}_{3} \mathrm{NHC}(\mathrm{OH})_{2}\right)$ and $\mathrm{P} 6\left(\mathrm{CH}_{3} \mathrm{OC}-644\right.$ $\left.(\mathrm{OH})^{+} \mathrm{NH}_{2}\right)$ isomers close in energy, $3.43 \mathrm{kcal} \mathrm{mol}^{-1}$ and 6.41645 $\mathrm{kcal} \mathrm{mol}^{-1}$, respectively, above protonated glycine at the 646 $\operatorname{CCSD}(\mathrm{T})$ level.

All reaction processes that could form $\left[\mathrm{H}_{6} \mathrm{C}_{2} \mathrm{O}_{2} \mathrm{~N}\right]^{+}$isomers 648 from the reaction between protonated hydroxylamine and 649 acetic acid are exothermic except for those initiated by the 650 
651 most stable isomer of protonated hydroxylamine which lead to 652 the P1 $\left(\mathrm{CH}_{3} \mathrm{CONH}_{2}{ }^{+} \mathrm{OH}\right)$ and $\mathrm{P} 7\left(\mathrm{CH}_{3} \mathrm{COHNOH}_{2}{ }^{+}\right)$ 653 isomers.

654 The study has been focused on the most abundant products, 655 denoted as $\mathrm{P} 1\left(\mathrm{CH}_{3} \mathrm{CONH}_{2}^{+} \mathrm{OH}\right), \mathrm{P} 2\left(\mathrm{CH}_{3} \mathrm{COONH}_{3}^{+}\right)$, and $656 \mathrm{P} 3\left(\mathrm{CH}_{3} \mathrm{C}(\mathrm{OH})^{+} \mathrm{ONH}_{2}\right)$, obtained from a previous ${ }^{26}$ chemical 657 dynamics simulations study on the reaction between 658 protonated hydroxylamine and acetic acid. Thus, for these 659 isomers a detailed analysis of the corresponding singlet 660 potential energy surface has been performed. From the analysis 661 of the potential energy surfaces, we can conclude that even if 662 the reactions of formation of $\mathrm{P} 2$ and $\mathrm{P} 3$ isomers are exothermic 663 processes, significant activation barriers were found in the 664 paths leading to these products. The only exothermic process $665\left(\Delta E=-23.9 \mathrm{kcal} \mathrm{mol}^{-1}\right.$ at the $\operatorname{CCSD}(\mathrm{T})$ level $)$ with no net 666 activation barrier was initiated by the high-energy isomer of 667 protonated hydroxylamine, which leads to the P1 $668\left(\mathrm{CH}_{3} \mathrm{CONH}_{2}{ }^{+} \mathrm{OH}\right)$ isomer. Therefore, the formation of $669 \mathrm{CH}_{3} \mathrm{CONH}_{2}{ }^{+} \mathrm{OH}$ could be feasible under interstellar con670 ditions from the reaction of the less stable isomer of 671 protonated hydroxylamine and acetic acid. Consequently, 672 from these results, the neutral isomer P1N ( $N$-hydroxyaceta673 mide, $\mathrm{CH}_{3} \mathrm{CONHOH}$ ) might be a candidate molecule to be 674 searched for in the interstellar medium.

675 The relevant spectroscopic parameters to rotational spec676 troscopy, harmonic and anharmonic frequencies, and IR 677 intensities are reported for $\left[\mathrm{H}_{6} \mathrm{C}_{2} \mathrm{O}_{2} \mathrm{~N}\right]^{+}$and $\left[\mathrm{H}_{5} \mathrm{C}_{2} \mathrm{O}_{2} \mathrm{~N}\right]$ 678 isomers. This information could aid in their laboratory 679 characterization by micro- and millimeter-wave spectroscopy 680 or astronomical search by radioastronomy or IR spectroscopy.

\section{$681 \square$ ASSOCIATED CONTENT}

\section{S Supporting Information}

683 The Supporting Information is available free of charge on the 684 ACS Publications website at DOI: 10.1021/acsearthspace685 chem.9b00053.

686 Geometry optimized for P1-P8 isomers (Table S1), 687 harmonic and anharmonic vibrational frequencies of 688 P1-P8 isomers (Table S2), geometry optimized for 689 P1N-P8N isomers (Table S3), and harmonic and 690 anharmonic vibrational frequencies of $\mathrm{P} 1 \mathrm{~N}-\mathrm{P} 8 \mathrm{~N}$ 691 isomers (Table S4) (PDF)

\section{AUTHOR INFORMATION}

\section{Corresponding Author}

694 *E-mail: carmen.barrientos@uva.es.

\section{ORCID}

696 Antonio Largo: 0000-0003-4959-4850

697 Carmen Barrientos: 0000-0003-0078-7379

698 Notes

699 The authors declare no competing financial interest.

\section{$700 \square$ ACKNOWLEDGMENTS}

701 Financial support from the Spanish Ministerio de Economía 702 Industria y Competitividad (Grant AYA2017-87515-P) and 703 the Junta de Castilla y León (Grant VA010G18) is gratefully 704 acknowledged. M.S.-N. acknowledges funding from the 705 Spanish "Ministerio de Ciencia, Innovación y Universidades" 706 under a Predoctoral FPU Grant (FPU17/02987).

\section{REFERENCES}

(1) Miller, S. L. A Production of Amino Acids under Possible 708 Primitive Earth Conditions. Science 1953, 117, 528-529. 709

(2) Johnson, A. P.; Cleaves, H. J.; Dworkin, J. P.; Glavin, D. P.; 710 Lazcano, A.; Bada, J. L. The Miller Volcanic Spark Discharge 711 Experiment. Science 2008, 322, 404.

(3) Pizzarello, S. The Chemistry of Life's Origin: A Carbonaceous 713 Meteorite Perspective. Acc. Chem. Res. 2006, 39, 231-237. 714

(4) Pizzarello, S.; Shock, E. The Organic Composition of 715 Carbonaceous Meteorites: The Evolutionary Story Ahead of 716 Biochemistry. Cold Spring Harbor Perspect. Biol. 2010, 2, a002105. 717

(5) Burton, A. S.; Stern, J. C.; Elsila, J. E.; Glavin, D. P.; Dworkin, J. 718 P. Understanding Prebiotic Chemistry through the Analysis of 719 Extraterrestrial Amino Acids and Nucleobases in Meteorites. Chem. 720 Soc. Rev. 2012, 41, 5459-5472.

(6) Ruiz-Mirazo, K.; Briones, C.; de la Escosura, A. Prebiotic 722 Systems Chemistry: New Perspectives for the Origins of Life. Chem. 723 Rev. 2014, 114, 285-366.

(7) Snyder, L. E.; Lovas, F. J.; Hollis, J. M.; Friedel, D. N.; Jewell, P. 725 R.; Remijan, A.; Ilyushin, V. V.; Alekseev, E. A.; Dyubko, S. F. A 726 Rigorous Attempt to Verify Interstellar Glycine. Astrophys. J. 2005, 727 619, 914-930.

728

(8) Cunningham, M. R.; Jones, P. A.; Godfrey, P. D.; Cragg, D. M.; 729 Bains, I.; Burton, M. G.; Calisse, P.; Crighton, N. H. M.; Curran, S. J.; 730 Davis, T. M.; Dempsey, J. T.; Fulton, B.; Hidas, M. G.; Hill, T.; 731 Kedziora-Chudczer, L.; Minier, V.; Pracy, M. B.; Purcell, C.; 732 Shobbrook, J.; Travouillon, T. A Search for Propylene Oxide and 733 Glycine in Sagittarius B2 (LMH) and Orion. Mon. Not. R. Astron. Soc. 734 2007, 376, 1201-1210.

(9) Jones, P. A.; Cunningham, M. R.; Godfrey, P. D.; Cragg, D. M. A 736 Search for Biomolecules in Sagittarius B2 (LMH) with the 737 AustraliaTelescope Compact Array. Mon. Not. R. Astron. Soc. 2007, 738 374, 579-589.

(10) Hollis, J. M.; Pedelty, J. A.; Snyder, L. E.; Jewell, P. R.; Lovas, F. 740 J.; Palmer, P.; Liu, S.-Y. A Sensitive Very Large Array Search for 741 SmallScale Glycine Emission Toward OMC-1. Astrophys. J. 2003, 588, 742 353-359.

(11) Altwegg, K.; Balsiger, H.; Bar-Nun, A.; Berthelier, J.-J.; Bieler, 744 A.; Bochsler, P.; Briois, C.; Calmonte, U.; Combi, M. R.; Cottin, H.; 745 De Keyser, J.; Dhooghe, F.; Fiethe, B.; Fuselier, S. A.; Gasc, S.; 746 Gombosi, T. I.; Hansen, K. C.; Haessig, M.; Jäckel, A.; Kopp, E.; 747 Korth, A.; Le Roy, L.; Mall, U.; Marty, B.; Mousis, O.; Owen, T.; 748 Rème, H.; Rubin, M.; Sémon, T.; Tzou, C. Y.; Hunter Waite, J.; Wurz, 749 P. Prebiotic Chemicals - Amino Acid and Phosphorus - in the Coma 750 of Comet 67P/Churyumov-Gerasimenko. Sci. Adv. 2016, 2, 751 No. e1600285.

(12) Ehrenfreund, P.; Bernstein, M.; Dworkin, J. P.; Sandford, S. A.; 753 Allamandola, L. The Photostability of Amino Acids in Space. 754 Astrophys. J. 2001, 550, L95-L99.

(13) Irvine, W. Extraterrestrial Organic Matter: A Review. Origins 756 Life Evol. Biospheres 1998, 28, 365-383. 757

(14) Herbst, E. The Chemistry of Interstellar Space. Chem. Soc. Rev. 758 2001, 30, 168-176.

(15) Snow, J. L.; Orlova, G.; Blagojevic, V.; Bohme, D. K. Gas-Phase 760 Ionic Syntheses of Amino Acids: $\beta$ versus $\alpha$. J. Am. Chem. Soc. 2007, 761 129, 9910-9917.

(16) Blagojevic, V.; Petrie, S.; Bohme, D. K. Gas-Phase Syntheses for 763 Interstellar Carboxylic and Amino Acids. Mon. Not. R. Astron. Soc. 764 2003, 339, L7-L11.

(17) Mehringer, D. M.; Snyder, L. E.; Miao, Y.; Lovas, F. J. 766 Detection and Confirmation of Interstellar Acetic Acid. Astrophys. J. 767 1997, 480, L71-L74.

(18) Remijan, A.; Snyder, L. E.; Liu, S.-Y.; Mehringer, D.; Kuan, Y.-J. 769 Acetic Acid in the Hot Cores of Sagitarrius B2(N) and W51. 770 Astrophys. J. 2002, 576, 264-273.

(19) He, J.; Vidali, G.; Lemaire, J.-M.; Garrod, R. T. Formation of 772 Hydroxylamine on Dust Grains Via Ammonia Oxidation. Astrophys. J. 773 2015, 799, 49. 
775 (20) Nishi, N.; Shinohara, H.; Okuyama, T. Photodetachment, 776 Photodissociation, and Photochemistry of Surfacemolecules of Icy 777 Solids Containing $\mathrm{NH}_{3}$ and Pure $\mathrm{H}_{2} \mathrm{O}$ Ices. J. Chem. Phys. 1984, 80, 778 3898-3910.

779 (21) Zheng, W.; Kaiser, R. I. Formation of Hydroxylamine $780\left(\mathrm{NH}_{2} \mathrm{OH}\right)$ in Electron-Irradiated Ammonia-Water Ices. J. Phys. 781 Chem. A 2010, 114, 5251-5255.

782 (22) Congiu, E.; Fedoseev, G.; Ioppolo, S.; Dulieu, F.; Chaabouni, 783 H.; Baouche, S.; Lemaire, J. L.; Laffon, C.; Parent, P.; Lamberts, T.; 784 Cuppen, H. M.; Linnartz, H. No Ice Hydrogenation: A Solid Pathway 785 to $\mathrm{NH}_{2} \mathrm{OH}$ Formation in Space. Astrophys. J., Lett. 2012, 750, L12. 786 (23) Charnley, S. B.; Rodgers, S. D.; Ehrenfreund, P. Gas-Grain 787 Chemical Models Of Star-Forming Molecular Clouds as Constrained 788 by ISO and SWAS Observations. Astron. Astrophys. 2001, 378, 10247891036.

790 (24) Jonusas, M.; Krim, L. A Possible Answer to the Mysterious 791 Non-Detection of Hydroxylamine in Space: The Thermal Desorption 792 Mechanism. Mon. Not. R. Astron. Soc. 2016, 459, 1977-1984.

793 (25) Barrientos, C.; Redondo, P.; Largo, L.; Rayón, V. M.; Largo, A. 794 Gas-Phase Synthesis of Precursors of Interstellar Glycine: A 795 Computational Study of the Reactions of Acetic Acid with 796 Hydroxylamine and its Ionized and Protonated Derivatives. Astrophys. 797 J. 2012, 748, 99.

798 (26) Jeanvoine, Y.; Largo, A.; Hase, W. L.; Spezia, R. Gas Phase 799 Synthesis of Protonated Glycine by Chemical DynamicsSimulations. J. 800 Phys. Chem. A 2018, 122, 869-877.

801 (27) Lattelais, M.; Pauzat, F.; Pilmé, J.; Ellinger, Y.; Ceccarelli, C. 802 About the Detectability of Glycine in the Interstellar Medium. Astron. 803 Astrophys. 2011, 532, A39.

804 (28) Demyk, K.; Wlodarczak, G.; Dartois, E. In Semaine de 805 l'Astrophysique Francaise, SF2A-2004, Jun. 14-18, 2004, Paris, France; 806 Combes, F., Barret, D., Contini, T., Meynadier, F., Pagani, L., Eds.; 807 EDP-Sciences, Les Ulis, France, 2004; p 493.

808 (29) Groner, P.; Winnewisser, M.; Medvedev, I. R.; De Lucia, C.; 809 Herbst, E.; Sastry, K. The Millimeter- and Submillimeter-Wave 810 Spectrum of Methyl Carbamate $\left[\mathrm{CH}_{3} \mathrm{OC}(: \mathrm{O}) \mathrm{NH}_{2}\right]$. Astrophys. J., 811 Suppl. Ser. 2007, 169, 28-36.

812 (30) Maris, A. On the Conformational Equilibrium of Glycolamide: 813 A Free Jet Millimetre-Wave Spectroscopy and Computational Study. 814 Phys. Chem. Chem. Phys. 2004, 6, 2611-2616.

815 (31) Becke, A. D. Density-Functional Thermochemistry. The Role 816 of Exact Exchange. J. Chem. Phys. 1993, 98, 5648-5652.

817 (32) Lee, C.; Yang, W.; Parr, R. G. Development of the Colle818 SalvettiCorrelation-Energy Formula into a Functional of the Electron 819 Density. Phys. Rev. B: Condens. Matter Mater. Phys. 1988, 37, 785820789.

821 (33) Dunning, T. H. Gaussian Basis Sets for Use in Correlated 822 Molecular Calculations. I. The Atoms Boron through Neon 823 andHydrogen. J. Chem. Phys. 1989, 90, 1007-1023.

824 (34) Kendall, R. A.; Dunning, T. H., Jr.; Harrison, R. J. Electron 825 Affinities of the First-Row Atoms Revisited. Systematic Basis Sets 826 andWave Functions. J. Chem. Phys. 1992, 96, 6796-6806.

827 (35) Møller, C.; Plesset, M. Note on an Approximation 828 Treatmentfor Many-Electron Systems. Phys. Rev. 1934, 46, 618-622. 829 (36) Woon, D. E.; Dunning, T. H. Gaussian Basis Sets for Use in 830 Correlated Molecular Calculations. III. The Atoms Aluminium831 through Argon. J. Chem. Phys. 1993, 98, 1358-1371.

832 (37) Barone, V. Anharmonic Vibrational Properties by a Full833 yAutomated Second-Order Perturbative Approach. J. Chem. Phys. 834 2005, 122, 014108.

835 (38) Raghavachari, K.; Trucks, G. W.; Pople, J. A.; Head-Gordon, M. 836 A Fifth-Order Perturbation Comparison of Electron Correlation837 Theories. Chem. Phys. Lett. 1989, 157, 479-483.

838 (39) Gonzalez, C.; Schlegel, H. B. An Improved Algorithm for 839 Reaction Path Following. J. Chem. Phys. 1989, 90, 2154-2161.

840 (40) Gonzalez, C.; Schlegel, H. B. Reaction Path Following in 841 MassweightedInternal Coordinates. J. Phys. Chem. 1990, 94, 55238425527.
(41) Frisch, M. J.; Trucks, G. W.; Schlegel, H. B.; Scuseria, G. E.; 843 Robb, M. A.; Cheeseman, J. R.; Scalmani, G.; Barone, V.; Petersson, 844 G. A.; Nakatsuji, H.; Li, X.; Caricato, M.; Marenich, A. V.; Bloino, J.; 845 Janesko, B. G.; Gomperts, R.; Mennucci, B.; Hratchian, H. P.; Ortiz, J. 846 V.; Izmaylov, A. F.; Sonnenberg, J. L.; Williams-Young, D.; Ding, F.; 847 Lipparini, F.; Egidi, F.; Goings, J.; Peng, B.; Petrone, A.; Henderson, 848 T.; Ranasinghe, D.; Zakrzewski, V. G.; Gao, J.; Rega, N.; Zheng, G.; 849 Liang, W.; Hada, M.; Ehara, M.; Toyota, K.; Fukuda, R.; Hasegawa, J.; 850 Ishida, M.; Nakajima, T.; Honda, Y.; Kitao, O.; Nakai, H.; Vreven, T.; 851 Throssell, K.; Montgomery, J. A., Jr.; Peralta, J. E.; Ogliaro, F.; 852 Bearpark, M. J.; Heyd, J. J.; Brothers, E. N.; Kudin, K. N.; Staroverov, 853 V. N.; Keith, T. A.; Kobayashi, R.; Normand, J.; Raghavachari, K.; 854 Rendell, A. P.; Burant, J. C.; Iyengar, S. S.; Tomasi, J.; Cossi, M.; 855 Millam, J. M.; Klene, M.; Adamo, C.; Cammi, R.; Ochterski, J. W.; 856 Martin, R. L.; Morokuma, K.; Farkas, O.; Foresman, J. B.; Fox, D. J. 857 Gaussian 16, Revision B.01; Gaussian: Wallingford, CT, USA, 2016. 858 (42) Stanton, J. F.; Gauss, J.; Harding, M. E.; Szalay, P. G. CFOUR, 859 Coupled-Cluster Techniques for Computational Chemistry, A Quantum 860 Chemical Program Package; 2013.

(43) Largo, L.; Rayon, V. M.; Barrientos, C.; Largo, A.; Redondo, P. 862 Stability of Protonated and Ionized Hydroxylamine in the Interstellar 863 Medium. Chem. Phys. Lett. 2009, 476, 174-177.

(44) Jobst, K. J.; Ruttink, P. J. A.; Terlouw, J. K. The Remarkable 865 Dissociation Chemistry of 2-Aminoxyethanol Ions 866 $\mathrm{NH}_{2} \mathrm{OCH}_{2} \mathrm{CH}_{2} \mathrm{OH}^{+}$Studied by Experiment and Theory. Int. J. 867 Mass Spectrom. 2008, 269, 165-176.

868

(45) Montgomery, J. A., Jr.; Frisch, M. J.; Ochterski, J. W.; 869 Petersson, G. A. A complete basis set model chemistry. VII. Use of the 870 Minimum Population Localization Method. J. Chem. Phys. 2000, 112, 871 $6532-6542$

872

(46) Pickett, H. M. The Fitting and Prediction of Vibration-Rotation 873 Spectra with Spin Interactions. J. Mol. Spectrosc. 1991, 148, 371-377. 874 